\title{
sciendo
}

CIVIL AND ENVIRONMENTAL ENGINEERING REPORTS

E-ISSN 2450-8594

CEER 2019; 29 (2): 117-155

DOI: $10.2478 /$ ceer-2019-0020

Original Research Article

\section{A STUDY ON THE EFFECT OF OPERATING PARAMETERS ON THE EFFICIENCY OF A MERCURY REMOVAL UNIT FROM NATURAL GAS}

\author{
Ahmed MOHSEN $^{1}$, Rania FAROUQ ${ }^{2}$ \\ Hassan A. FARAG ${ }^{3}$, Mostapha SALEM ${ }^{3}$ \\ ${ }^{1}$ Operation Department, Port-Said NGL Plant, United Gas Derivatives Company (UGDC), \\ Port-Said/Damietta International Coastal Road, Port Said, Egypt \\ ${ }^{2}$ Petrochemical Department, Faculty of Engineering, Pharos University, Canal El \\ Mahmoudeya St. Semouha, Alexandria, Egypt \\ ${ }^{3}$ Chemical Engineering Department, Faculty of Engineering, Alexandria University, P. O. \\ Alexandria, Egypt
}

\begin{abstract}
In this study, an industrial fixed-bed for mercury adsorption from natural gas, was evaluated by mathematical models. Equilibrium isotherms, kinetics equations, and adsorption models were applied to available data to evaluate sorbent characteristics, and then study bed's performance under different case studies. Models solutions are evaluated by linear-regression and coefficient of determination. The study confirmed that the system is characterized by irreversible equilibrium. Examining of kinetics equations indicated the inclusion of chemisorption and intra-particle diffusion as ratelimiting steps. Bohart-Adams model was found the best fitting model with good match between model's assumptions and available bed's information. Model prediction for bed's design-basis was examined and found good match with manufacturer's data-sheet.
\end{abstract}

Keywords: Mercury, Natural Gas, Adsorption, Chemisorption, Fixed Bed,

Mathematical Models

\footnotetext{
${ }^{2}$ Corresponding author: e-mail: rania.farouq@pua.edu.eg, telephone: 00201002706756
} 


\section{INTRODUCTION}

Natural gas is one of the most important energy sources because it is a cheap and clean fossil fuel. In addition to hydrocarbons, natural gas is contaminated with different impurities such as water and acid gases.

Mercury traces naturally exist in natural gas in different concentrations around the world. Although mercury exists in traces, it has severe effects on the environment and on the energy industry due to extreme toxic nature of all its compounds, so it has a considerable interest in research for efficient removal. It is primarily removed from natural gas by efficient adsorption process, and such processes have been studied and developed extensively due to its criticality.

Activated carbon and silica gel were in common use in adsorption before the development of molecular sieve adsorbents particularly synthetic zeolites in the late 1950s, which lead to the potential of separation by adsorption process, and various zeolite structures have been tailored. Commercial trapping products differ in the nature of the trapping agent and/or the support material.

The principle types of mercury trapping agents are elemental sulfur, metal sulfides, metal oxides, activated carbon, iodine, silver, and gold [1-6]. Silver and gold active phases are simply based on effective amalgamation removal with regeneration potential.

In mercury adsorption, the fixation of mercury in a stable form is a necessary characteristic desired in adsorbents to consider the environmental hazard of disposing the spent adsorbents after being saturated. Accordingly, some recent studies are available for adsorbents capable of keeping the adsorbed mercury fixed in stable form [7]. In addition, some studies focused on the modeling of the adsorption mechanism of mercury such as Chung et al. model, which was developed for mercury adsorption onto active sites of impregnated activated carbon [8]. Another study by Ren et al. who utilized a successful representative model considering surface equilibrium and mass transfer mechanisms to investigate mercury adsorption from flue gases by activated carbon and fly ash [9]. Also Carla et al. investigated the stable chemisorption of mercury from natural gas by using laboratory synthesized hydroxyapatites modified with copper sulfide as active sites for chemical reaction and utilized a model considering adsorption, diffusion, and chemical reaction [10]. Sasmaz et al. investigated the chemistry of mercury adsorption onto brominated activated carbon where chemisorption was found the likely mechanism [3]. Skodras et al. studied mercury and PCBs adsorption from gas phase using different types of activated carbon where they found increase in efficiency by adding impregnated sulfur active agent for chemisorption mechanism [11]. Meserole et al. studied mercury removal from flue gases in ducts by sorbent injection, and presented a theoretical model that combines sorbent characteristics (extracted from 
experimental results), mass transfer characteristics of the system, Freundlich equilibrium isotherm, the surface area available for sorption, and the residence time, but did not incorporate any terms to account for intraparticle diffusion [12]. Flora et al. performed studies for mercury removal from flue gases by activated carbon injection, which are similar to the previous mentioned study by Meserole et al. in work and results, but they employed a two-stage model followed by sensitivity analysis [13, 14]. Similar experimental work and modeling attempts were investigated by Chen and co-workers, Serre et al., and Scala [15-19]. Many other researches thoroughly deal with experimental evaluation for the capability of various adsorbents to remove effectively the mercury species [1-6, 20-51].

Hence, chemical trapping of mercury in the form of cinnabar, a stable nonvolatile mercury ore, is the most commonly used mercury removal method for natural gas [52-55]. In this work, an industrial mercury removal bed was studied by evaluating bed and adsorbents characteristics through applying equilibrium isotherms, various kinetic expressions, and various adsorption mathematical models to the available breakthrough data.

\section{MATHEMATICAL MODELING OF MERCURY ADSORPTION UNIT}

The unit is composed of only one fixed bed packed with one of the available commercial non-regenerative products for mercury adsorption. The adsorbents are metal sulfide active agents that are chemically retained within activated alumina solid carrier. The particles used are beads of 2 to $4 \mathrm{~mm}$ diameter range and the material has excellent surface area and porosity characteristics in addition to relatively larger pore size ( $>80$ Angstrom) to avoid the risk of capillary condensation and eliminate the risk of deactivation by liquid phase.

Adsorption of mercury can be described in two steps; the first step is the physical adsorption of mercury from the gas phase to the solid surface by low energy Van-der-Waals forces. This process is normally reversible due to weak linkage and can be considered slightly exothermic, so the equilibrium is promoted by lower temperature and high sorbate concentration. The second step is the trapping (fixation) of adsorbed mercury by chemical reaction with the active phase (agent) supported within the porous structure of particles (carrier). This process is irreversible chemical reaction, under mild conditions, due to stronger linkage involving an exchange of electrons and for this reason, the whole process is called chemisorption process[56].

$$
\mathrm{Hg}+2 \mathrm{MS} \rightarrow \mathrm{HgS} \text { (Mercury Sulfide) }+\mathrm{M}_{2} \mathrm{~S}
$$


In order to study the dynamics of MRU bed, all available bed information and adsorbent characteristics were collected for better initial assumptions regarding the equilibrium relationship and adsorption kinetics. Then, obtained a set of breakthrough data, by personal contact, from the adsorbent manufacturer to use it in testing various known mathematical models by linear regression, and perform all possible calculations to help in studying the system. The data were obtained for two particle sizes, $4 \mathrm{~mm}$ and $2 \mathrm{~mm}$, as the bed is packed with a range of 2-4 $\mathrm{mm}$ adsorbents and the breakthrough curves are shown in the following plot.

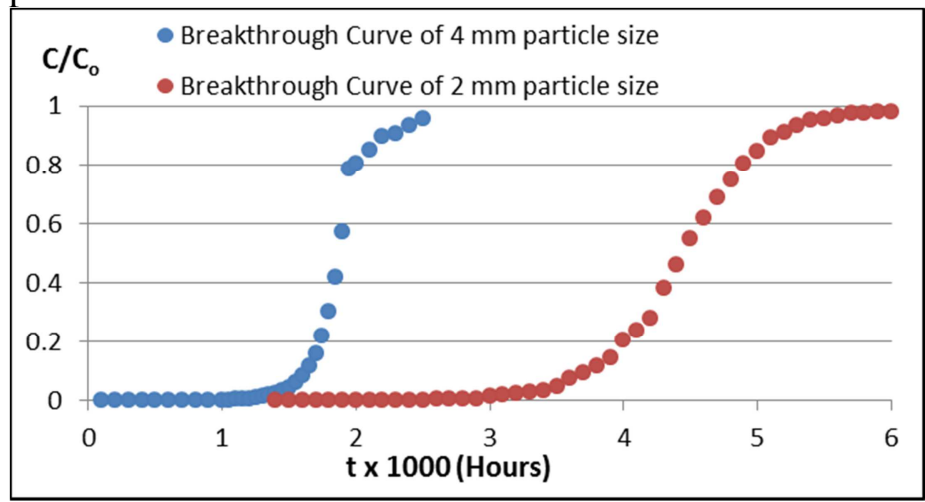

Fig. 1. Experimental Breakthrough Curves

These equilibrium data represent the results of tests performed and owned by the manufacturer under conditions similar to the NGL plant operating conditions. The operating conditions are summarized in the following table.

Table. 1. Design Basis and Operating Conditions

\begin{tabular}{|c|c|}
\hline Maximum Feed Gas Flow Rate & $1,350 \mathrm{MMSCFD}$ \\
\hline Maximum Inlet Mercury Concentration & $20 \mu \mathrm{g} / \mathrm{Nm}^{3}$ \\
\hline Outlet Mercury Concentration & Below $0.01 \mu \mathrm{gg} / \mathrm{Nm}^{3}$ \\
\hline Lifetime & $5 \mathrm{Years}$ \\
\hline Bed Diameter & $5 \mathrm{Meters}$ \\
\hline Bed Height & $2.50 \mathrm{Meters}$ \\
\hline Phase & Dry Gas \\
\hline Temperature & $15-40^{\circ} \mathrm{C}(\mathrm{Ambient})$ \\
\hline Pressure & $60-70 \mathrm{Barg}$ \\
\hline Flow direction & Downward \\
\hline Design C5+ Mole\% & 0.3837 \\
\hline Molecular Weight & 18 \\
\hline Density & $57.6 \mathrm{Kg} / \mathrm{m}^{3}$ \\
\hline Viscosity & $0.011 \mathrm{cP}$ \\
\hline Maximum Pressure Drop & $1 \mathrm{bar}$ \\
\hline
\end{tabular}




\subsection{Adsorption Equilibrium}

Both Langmuir and Freundlich isotherm relationships were chosen to be applied to the available numerical data to get insight into adsorption equilibrium of the system.

\subsubsection{Freundlich Equilibrium Isotherm}

Freundlich equilibrium relationship is given by:

$$
\mathrm{q}=\mathrm{K} \mathrm{C}^{1 / \mathrm{n}}
$$

The Linear form is rearranged as:

$\ln \mathrm{q}=\ln \mathrm{K}+1 / \mathrm{n} \ln \mathrm{C}$

Where $\mathrm{K}$ is equilibrium constant indicative for adsorption capacity and $\mathrm{n}$ is a constant representing the adsorption intensity or the degree of favorability where $1 / \mathrm{n}$ between 0 to 1 is indication of a favorable adsorption and 1 reduces to linear Henry law [57].

\subsubsection{Langmuir Equilibrium Isotherm}

Equilibrium relationship:

$\theta=\frac{\mathrm{q}}{\mathrm{qs}}=\frac{\mathrm{bc}}{1+\mathrm{bc}}$

The Linear form is rearranged as:

$\frac{\mathrm{Ce}}{\mathrm{qe}}=\frac{1}{\mathrm{~b} \mathrm{qs}}+\frac{\mathrm{Ce}}{\mathrm{qs}}$

By Langmuir model, a good fit of many experimental isotherms can be achieved just by optimum selection of equilibrium constants $\mathrm{b}$ (equilibrium constant = $\mathrm{K}_{\mathrm{ads}} / \mathrm{K}_{\mathrm{des}}$ ) and $\mathrm{q}_{\mathrm{s}}$ (saturation capacity). Higher values of $\mathrm{b}$ means higher adsorption rate relative to desorption rate and accordingly higher removal $[58,59]$.

\subsection{Adsorption Kinetics}

The following kinetics equations were applied to the equilibrium data for system's kinetics evaluation by linear regression.

1- Lagergren Pseudo-first order

2- Pseudo-second order

3- Elovich's model

4- Weber and Morris

5- Diffusion-Chemisorption Model

6- Linear Driving Force diffusion 


\subsubsection{Lagergren Pseudo-First Order}

The kinetic expression is given by:

$\frac{\partial q}{\partial t}=k\left(q_{e}-q_{t}\right)$

The linear form is rearranged as:

$\log \left(q_{e}-q_{t}\right)=\log q_{e}-\frac{k}{2.303} t$

Where $\mathrm{q}_{\mathrm{t}}$ is mercury concentration in solid phase $\mathrm{Kg} / \mathrm{m}^{3}$ at time $\mathrm{t}$ and $\mathrm{q}_{\mathrm{e}}$ is equilibrium concentration and $\mathrm{k}$ is kinetic constant (1/ time unit) [60].

\subsubsection{Pseudo-Second Order}

The kinetic expression is given by:

$\frac{\partial q}{\partial t}=k\left(q_{e}-q_{t}\right)^{2}$

The linear Form is rearranged as:

$\frac{t}{q_{t}}=\frac{1}{k q_{e}{ }^{2}}+\frac{1}{q_{e}} t$

Where initial adsorption rate is $h=k q_{e}^{2}, \mathrm{q}_{\mathrm{t}}$ is mercury concentration in solid phase $\mathrm{Kg} / \mathrm{m}^{3}$ at time $\mathrm{t}$ and $\mathrm{q}_{\mathrm{e}}$ is equilibrium concentration and $\mathrm{k}$ is kinetic constant $\left(\mathrm{m}^{3} / \mathrm{Kg}\right.$-hr) $[61,62]$.

\subsubsection{Elovich's Model}

The kinetic expression is given by:

$\frac{\partial q}{\partial t}=\alpha \exp (-\beta q)$

The linear Form is rearranged as:

$q_{t}=\frac{1}{\beta} \ln (\alpha \beta)+\frac{1}{\beta} \ln t$

Where $\alpha$ is the initial adsorption rate, $\beta$ is desorption constant or the relationship between the degree of surface coverage and activation energy of chemisorption, and $\mathrm{q}_{\mathrm{t}}$ is mercury concentration in solid phase $\mathrm{Kg} / \mathrm{m}^{3}$ at time $\mathrm{t}$ [63].

\subsubsection{Weber and Morris Model}

The kinetic expression:

$q_{t}=k_{i d} \sqrt{t}+C$

Where $k_{i d}$ is diffusion rate constant $=\frac{\sigma \sqrt{ } D}{R_{p} \sqrt{ } \pi}$ and $C$ intercept indicates the external

film thickness, where the higher $C$, the higher external film effects [64].

\subsubsection{Diffusion-Chemisorption Model}


The kinetic expression is given by:

$\frac{\partial q}{\partial t}=n K_{D C} t^{n-1}\left(q_{e}-q_{t}\right)^{2} / q_{e}{ }^{2}$

The linear form, with $\mathrm{n}=0.5$ as per Sutherland analysis, is rearranged as:

$\frac{t^{0.5}}{q_{t}}=\frac{1}{q_{e}} t^{0.5}+\frac{1}{K_{D C}}$

Where Initial adsorption rate is expressed by:

$K_{i}=K_{D C}^{2} / q_{e}$

By plotting $\sqrt{t} / q_{t}$ versus $\sqrt{t}$, it would be linear in case of fitting the data to the kinetic expression derivation assumptions and the system kinetics can be represented by this proposed rate equation [65].

\subsubsection{Linear Driving Force diffusion Expression}

The kinetic expression is given by:

$\operatorname{Ln}(1-\alpha)=k t$

Where $\alpha$ is the fractional attainment of equilibrium $q / q_{e}$ and $k$ is diffusion time constant.

By plotting $\operatorname{Ln}(1-\alpha)$ versus $t$, it would be linear in case of fitting the data to the kinetic expression assumptions that the particle diffusion is the governing rate limiting step and the system kinetics is described by this proposed rate formula [66].

\subsection{Adsorption Modeling}

The adsorption models were chosen based on the probability of matching the system's available information with the assumptions that were proposed to derive these mathematical models.

The following models were used to test the fitting of the breakthrough curves using relationships between time and mercury concentration in gas phase rearranged in linear forms.

\subsubsection{Zhang and Cheng Model}

This model was developed for a catalytic reaction in a fixed bed packed with carbon, and was based on the following assumptions [67].

1. Physical adsorption with linear isotherm

$$
q=K_{i} C
$$

2. Simultaneous catalytic reaction assuming first order reaction equation $R=K C \Phi$

3. Catalyst deactivation by covering active sites with the reaction products assuming first order deactivation function

$\frac{\partial \Phi}{\partial t}=K_{d} \Phi$ 
The solution is given by:

$\Phi=\exp \left(-K_{d} t\right)$

where $\mathrm{R}$ is the reaction rate $\left(\mathrm{Kg} / \mathrm{m}^{3}-\mathrm{hr}\right), \mathrm{K}$ is the reaction rate constant $\left(\mathrm{hr}^{-1}\right), C$ is the adsorbate concentration in the gas stream $\left(\mathrm{Kg} / \mathrm{m}^{3}\right)$, $\mathrm{t}$ is time (hr), $\Phi$ is the deactivation function (dimensionless), and $K_{d}\left(\mathrm{hr}^{-1}\right)$ is the deactivation rate constant.

4. Ideal plug flow with no axial dispersion

5. Isothermal adsorption

6. The continuity equation of the fixed bed is given by: $\frac{\partial C}{\partial t}+v \frac{\partial C}{\partial x}+\frac{1-\varepsilon}{\varepsilon} \frac{\partial q}{\partial t}+R=0$

Where $v$ is superficial velocity $(\mathrm{m} / \mathrm{hr}), x$ is the distance from the bed inlet $(\mathrm{m}), \varepsilon$ is bed porosity (dimensionless), and $q$ is the adsorbate concentration in the adsorbent ( $\mathrm{Kg}$ adsorbate $/ \mathrm{m}^{3}$ adsorbent).

The partial differential equation of continuity was solved using the boundary conditions:

- At $x=0, t>0, C=C_{o}$

- At $t=0, x>0, C=0$

The following solution was obtained:

$\operatorname{LnLn} \frac{C_{o}}{C}=\alpha-K_{d} t$

Where

$\alpha=\operatorname{Ln} \frac{K}{\theta K_{d}}+\operatorname{Ln}\left(\exp \left(K_{d} \Theta L / v\right)-1\right)$

$\theta=1+\frac{K_{i}(1-\varepsilon)}{\varepsilon}$

$L$ is the length of the bed (m).

\subsubsection{Wolborska Model}

The model was developed by considering two regions in breakthrough curve where the adsorption front is migrating through the column in different ways. The model was developed to describe the low concentration region of the breakthrough curve in the range of $\mathrm{C} / \mathrm{C}_{o}$ from $10^{-5}$ to 0.05 . It was assumed that adsorption rate is controlled by the external mass transfer resistance [68].

The continuity equation is given by:

$\frac{\partial C}{\partial t}+v \frac{\partial C}{\partial x}+\frac{\partial q}{\partial t}=D_{L} \frac{\partial^{2} C}{\partial x^{2}}$

where $C$ is the adsorbate concentration in the gas phase ( $\mathrm{Kg}$ adsorbate $/ \mathrm{m}^{3}$ gas), $t$ is time (s), $v$ is the superficial velocity $(\mathrm{m} / \mathrm{s}), q$ is the adsorbate concentration in the solid phase ( $\mathrm{Kg}$ adsorbate $/ \mathrm{m}^{3}$ adsorbent), $D$ is axial diffusion coefficient, and $x$ is the distance from the column inlet (m).

The initial condition at $t=0$ is $C(z, 0)=0, q(z, 0)=0$. 
The boundary conditions are at $z=0, C(0, t)=C_{o}$ (inlet concentration), and at $z$ $=\infty, c(\infty, t)=0$.

By introducing new variables and rearranging then continuity equation becomes:

$(v-w) \frac{\partial C}{\partial t}-w \frac{\partial q}{\partial x}=D_{L} \frac{\partial^{2} C}{\partial x^{2}}$

and the initial and boundary conditions are $C(x, 0)=0, q(x, 0)=0, C(0, \tau)=C_{o}$, and $C(\infty, \tau)=0$.

The kinetic equation for external resistance is given by:

$\frac{\partial q}{\partial t}=\beta\left(C-C_{\mathrm{i}}\right)$

Where $C_{i}$ is concentration at gas-solid interface and by assuming quick intraparticle diffusion then $C_{i}<<C$ and kinetic equation becomes:

$w \frac{\partial q}{\partial x}=\beta C$

Rearranging continuity equation gives:

$\frac{\partial^{2} C}{\partial x^{2}}-\frac{(v-w)}{D} \frac{\partial C}{\partial x}-\frac{\beta C}{D}=0$

The linear solution form is obtained by Wolborska and given by:

$\operatorname{Ln} \frac{C}{C_{o}}=\frac{\beta C_{o}}{q_{o}} t-\frac{\beta L}{v}$

By plotting $\operatorname{Ln} \frac{C}{C_{o}}$ versus $t$, it would be linear in case the model is fitting the breakthrough data.

\subsubsection{Clark Model}

The model was developed based on the following assumptions:

1. Mass balance over a finite element of the bed is given by:

$$
J=\frac{v A C-v A(C-\Delta C)}{A \Delta Z}
$$

Where $J$ is the mass transfer rate per unit reactor volume $\left(\mathrm{Kg}\right.$ adsorbate/(s-m $\left.\left.{ }^{3}\right)\right)$, $v$ is the superficial velocity of gas per unit of cross-sectional area (m/(s-m2)), $A$ is the column cross sectional area $\left(\mathrm{m}^{2}\right)$, and $C$ is the gas phase adsorbate concentration into the differential element volume $\left(\mathrm{Kg} / \mathrm{m}^{3}\right)$, and $z$ is the bed height (m).

2. Mass transfer limitations are described as:

$$
v \frac{\partial C}{\partial z}=K_{t}\left(C-C_{e}\right)
$$

Where $\mathrm{K}_{\mathrm{t}}$ is the mass transfer coefficient in $\left(\mathrm{s}^{-1}\right)$, and $C_{e}$ is the equilibrium adsorbate concentration at the gas-solid interface ( $\mathrm{Kg}$ adsorbate $/ \mathrm{m}^{3}$ adsorbent).

3. Fruendlich isotherm for equilibrium is the governing isotherm formula.

$$
q=K C^{1 / n}
$$

Where $K$ is the equilibrium constant and $1 / n$ is the slope of the isotherm.

By simplifying and rearranging, the final solution obtained by Clark becomes: 
$\operatorname{Ln}\left[\left(\frac{C_{o}}{C}\right)^{\wedge(n-1)}-1\right]=-r t+\operatorname{Ln} A$

Where $\mathrm{n}$ does not equal one and by plotting $\operatorname{Ln}\left[\left(\frac{C_{o}}{C}\right)^{\wedge^{(n-1)}}-1\right]$ versus $t$, it would be linear in case the model is fitting the breakthrough data [69].

\subsubsection{Bohart \& Adams Model}

The model was developed based on the following assumptions [70].

1. One trace component adsorption

2. Adsorption with simultaneous chemical reaction (Chemisorption)

3. Irreversible adsorption isotherm $q=0$ at $C=0$ and $q=q_{s}$ at $C>0$

4. Ideal plug flow with negligible axial dispersion

5. Mass balance (continuity) equation for the fixed bed is given by: $\frac{\partial C}{\partial t}+v \frac{\partial C}{\partial x}+\frac{1-\varepsilon}{\varepsilon} \frac{\partial q}{\partial t}=0$

Where $C$ is the gas phase adsorbate concentration $\left(\mathrm{Kg}\right.$ adsorbate $/ \mathrm{m}^{3}$ gas), $t$ is time (hr), $v$ is superficial velocity of the gas stream $(\mathrm{m} / \mathrm{hr}), x$ is distance from the column inlet (m), $\varepsilon$ is bed porosity (dimensionless), and $q$ is the adsorbate concentration in the adsorbent $\left(\mathrm{Kg}\right.$ adsorbate $/ \mathrm{m}^{3}$ adsorbent) [86].

6. Adsorption kinetics are described by quasichemical rate law given by:

$\frac{\partial q}{\partial t}=k C\left(q_{s}-q\right)$

Where $q_{s}$ is the saturation capacity of $q$ that corresponds to the equilibrium condition at the gas/adsorbent interface $\left(\mathrm{Kg}\right.$ adsorbate $/ \mathrm{m}^{3}$ adsorbent), and $k$ is the kinetic constant. The rate of adsorption (quasichemical rate law) is proportional to the gas-phase adsorbate concentration, and to the remaining fraction of the adsorbent capacity, which still not occupied.

The differential continuity equation was solved by Cooney as below [58, 71-72].

$$
\frac{C}{C_{o}}=\frac{e^{t}}{e^{t}+e^{z}-1}
$$

Where

$$
\begin{aligned}
& t=K C_{o}\left(t-\frac{x}{v}\right) \\
& z=\frac{K q_{s} x}{v} \frac{\varepsilon}{1-\varepsilon}
\end{aligned}
$$

By rearranging, the following is the linear form of the model:

$$
\operatorname{Ln} \frac{C_{o}-C}{C}=-K C_{o}\left(t-\frac{x}{v}\right)+\operatorname{Ln}[\exp (z)+1]
$$


By plotting $\operatorname{Ln} \frac{C_{0}-C}{C}$ versus $\left(t-\frac{L}{v}\right)$, it would be linear in case of fitting the proposed model by Bohart \& Adams to the breakthrough data.

\section{RESULTS AND DISCUSSIONS}

\subsection{Studying Adsorption Equilibrium}

\subsubsection{Applying Freundlich Isotherm}

By plotting $\operatorname{Ln}(q)$ versus $\ln (C)$, Figures 2 and 3 indicate the results of linear regression where it would be linear in case of conforming the assumed empirical form of Freundlich Isotherm.
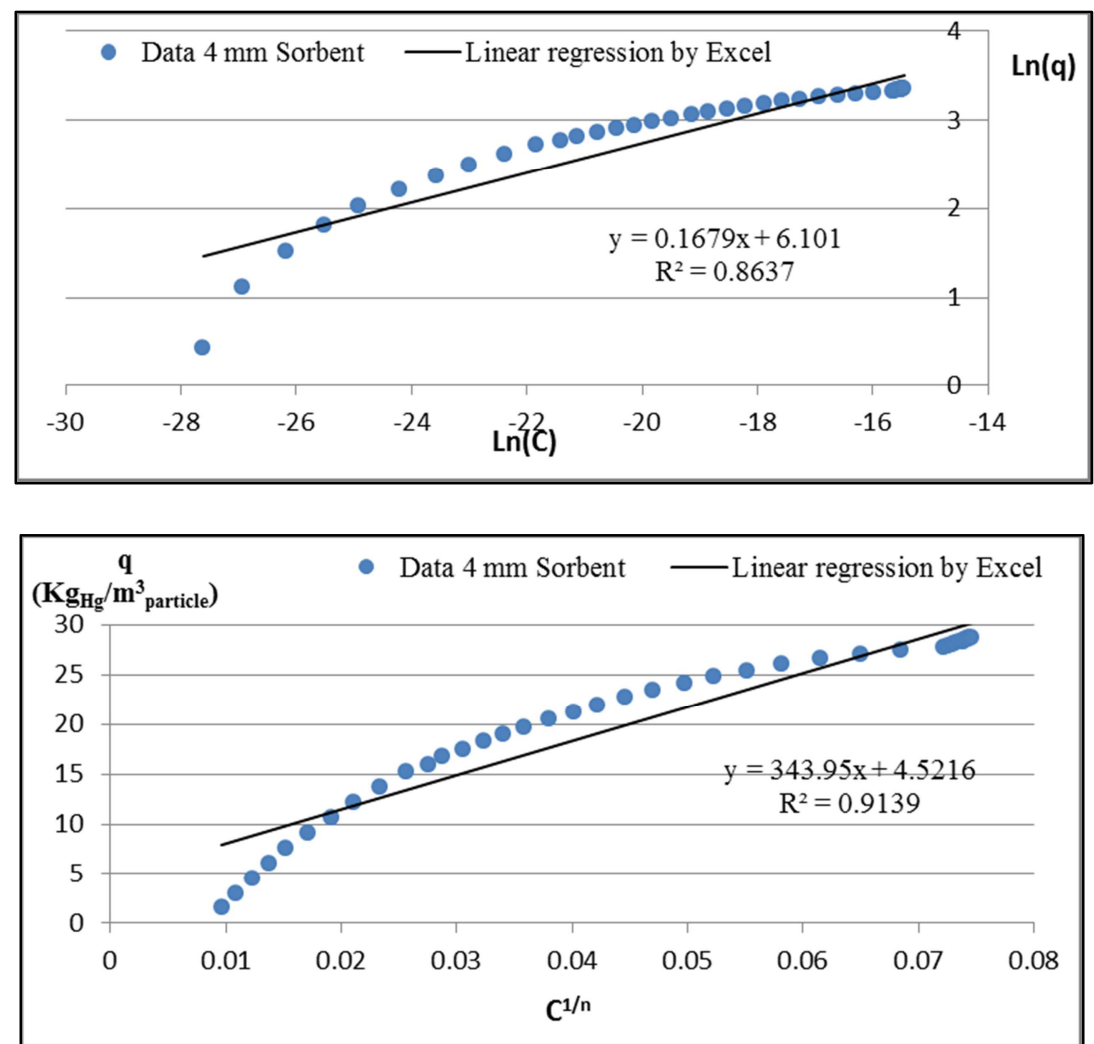

Fig. 2. Freundlich Isotherm Linear Regression with 4 mm Adsorbent 

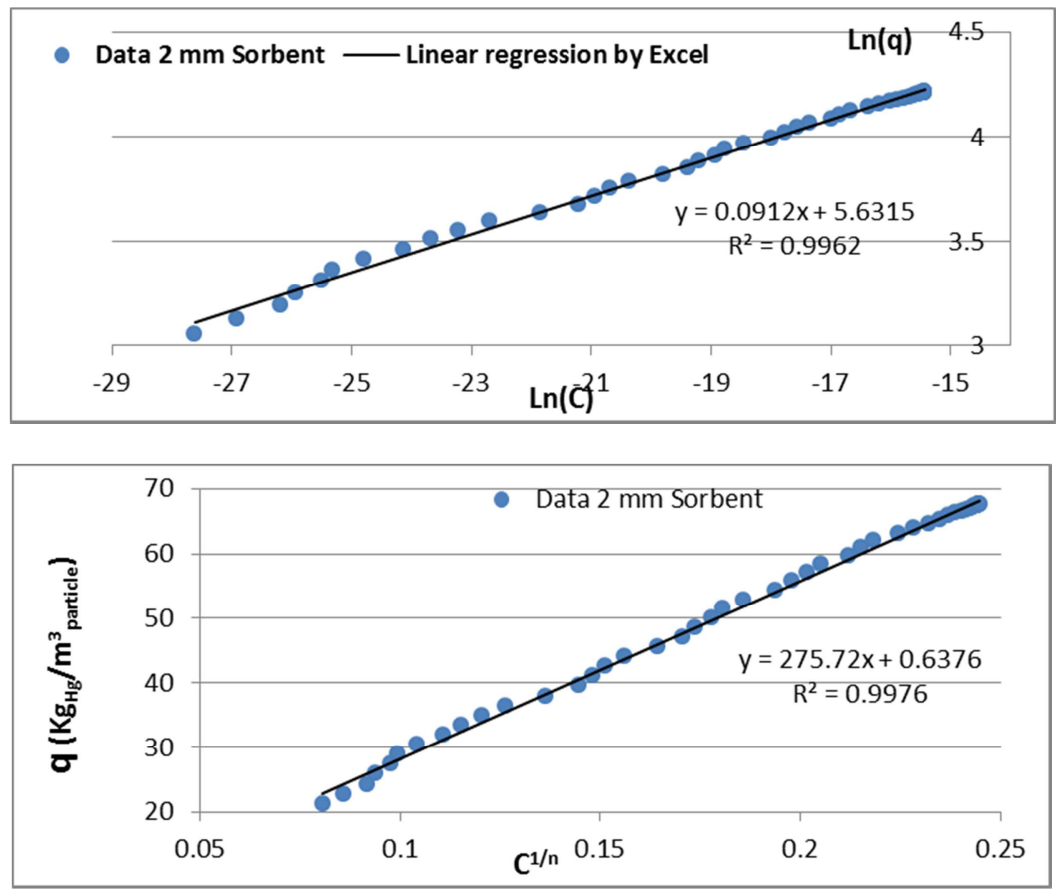

Fig. 3. Freundlich Isotherm Linear Regression with $2 \mathrm{~mm}$ Adsorbent

For $4 \mathrm{~mm}$ particle size, best fit can be obtained for the plot of $\mathrm{q}$ versus $\mathrm{C}^{1 / \mathrm{n}}$ by setting $1 / \mathrm{n}<0.05$, however it was calculated as 0.1679 from the slope of $\ln (\mathrm{q})$ versus $\operatorname{Ln}(\mathrm{C})$, which is indicative of high favorable equilibrium (irreversible isotherm). For $2 \mathrm{~mm}$ particle size, best fit is obtained with $1 / \mathrm{n}=0.0912(\mathrm{n}=$ 10.9649) as calculated from the slope of $\ln (\mathrm{q})$ versus $\operatorname{Ln}(\mathrm{C})$, which is indicative of also high favorable adsorption.

\subsubsection{Applying Langmuir Isotherm}

By plotting $C_{e} / q_{t}$ versus $C_{e}$, the following figures $(4,5)$ indicate results of linear regression where it would be linear in case of conforming Langmuir equilibrium isotherm. 


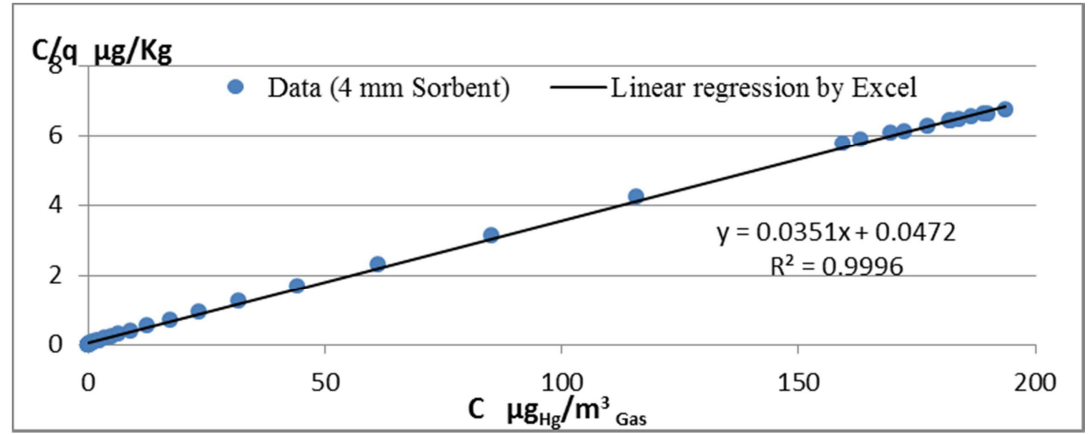

Fig. 4. Langmuir Isotherm Linear Regression with 4 mm Adsorbent

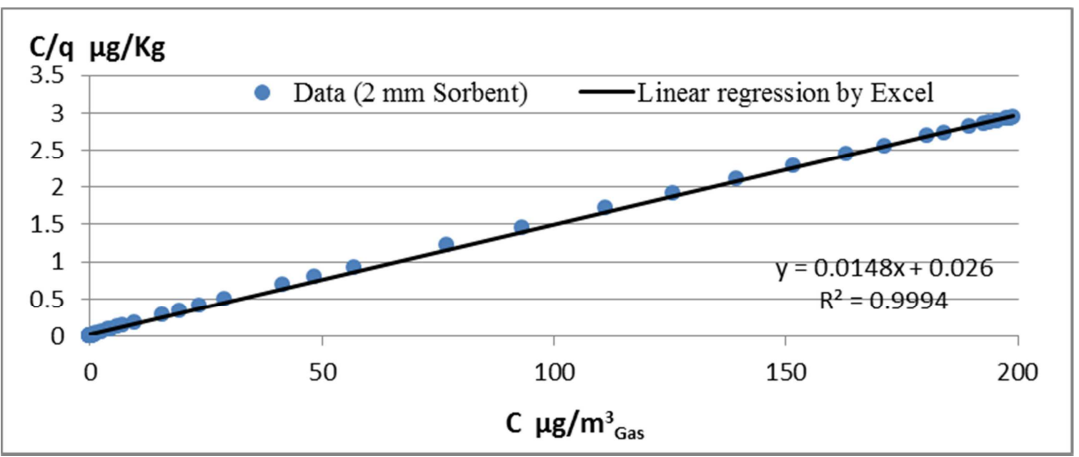

Fig. 5. Langmuir Isotherm Linear Regression with $2 \mathrm{~mm}$ Adsorbent

As show in table 2, both particles show ideal fit to Langmuir isotherm as expected due to matching system's information with Langmuir assumptions. $\mathbf{R}^{2}$ values are 0.9996 and 0.9994 and equilibrium constants "b" are calculated with obtaining much high values indicating irreversible isotherm, while saturation capacity $\mathrm{q}_{\mathrm{s}}$ where calculated very close to the figures calculated from the breakthrough data.

Table. 2. Calculated Langmuir Constants

\begin{tabular}{|c|c|c|c|}
\hline Particle Size & $\mathbf{R}^{\mathbf{2}}$ & $\begin{array}{c}\mathbf{q}_{\mathbf{s}} \\
\text { gram }_{\mathbf{H g}} / \mathbf{c m}_{\text {sorbent }}^{\mathbf{3}} \\
\text { from Langmuir }\end{array}$ & $\begin{array}{c}\mathbf{q}_{\mathbf{s}} \\
\text { gram }_{\mathbf{H g}} / \mathbf{c m}_{\text {sorbent }}^{\mathbf{3}} \\
\text { from breakthrough data }\end{array}$ \\
\hline $4 \mathrm{~mm}$ & 0.9996 & 0.0285 & 0.02896 \\
\hline $2 \mathrm{~mm}$ & 0.9994 & 0.0676 & 0.0682 \\
\hline
\end{tabular}




\subsection{Studying Adsorption Kinetics}

\subsubsection{Testing Lagergren Pseudo-First Order}

By plotting $\log \left(q_{e}-q_{t}\right)$ versus time, the following figures indicate the results of linear regression where it would be linear in case of conforming the proposed kinetics rate equation with considering that $q_{t}$ does not equal $q_{e}$.

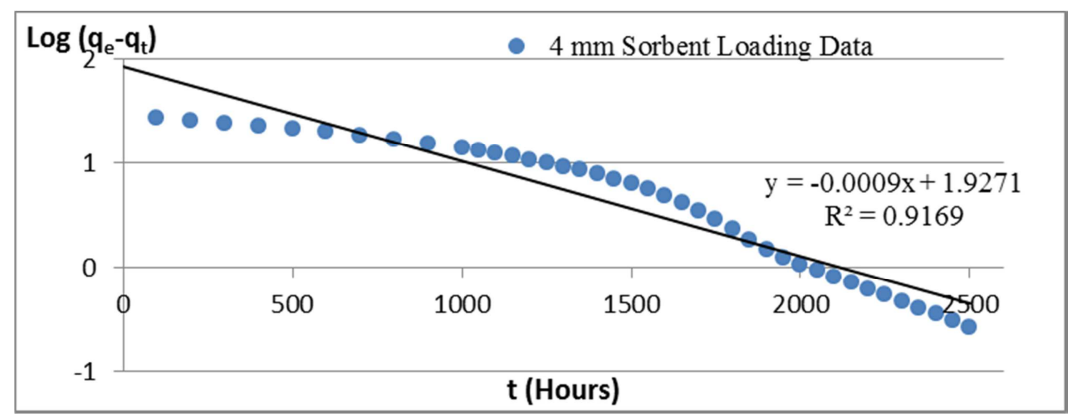

Fig. 6. Testing Lagergren Pseudo-First Order with 4 mm Adsorbent

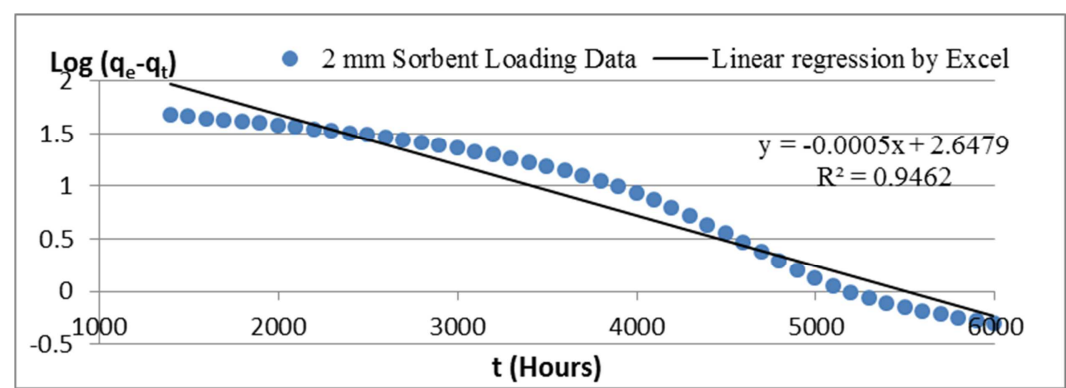

Fig. 7. Testing Lagergren Pseudo-First Order with 2 mm Adsorbent

Figures 6 and 7 show that the expression gives moderate fit with $\mathrm{R}^{2}$ values of 0.9169 and 0.9462 at $4 \mathrm{~mm}$ and $2 \mathrm{~mm}$ particle size respectively.

\subsubsection{Testing Pseudo-Second Order Equation}

By plotting $\frac{t}{q_{t}}$ versus time, the following figures indicate the results of linear regression where it would be linear in case of fitting the data to the kinetics equation. 


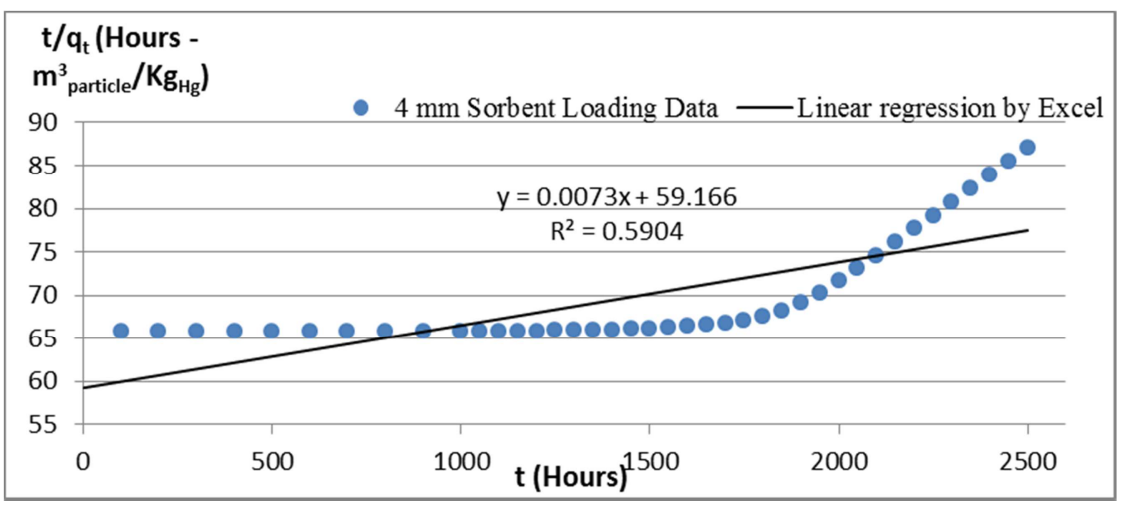

Fig. 8. Testing Pseudo-Second Order with $4 \mathrm{~mm}$ Adsorbent

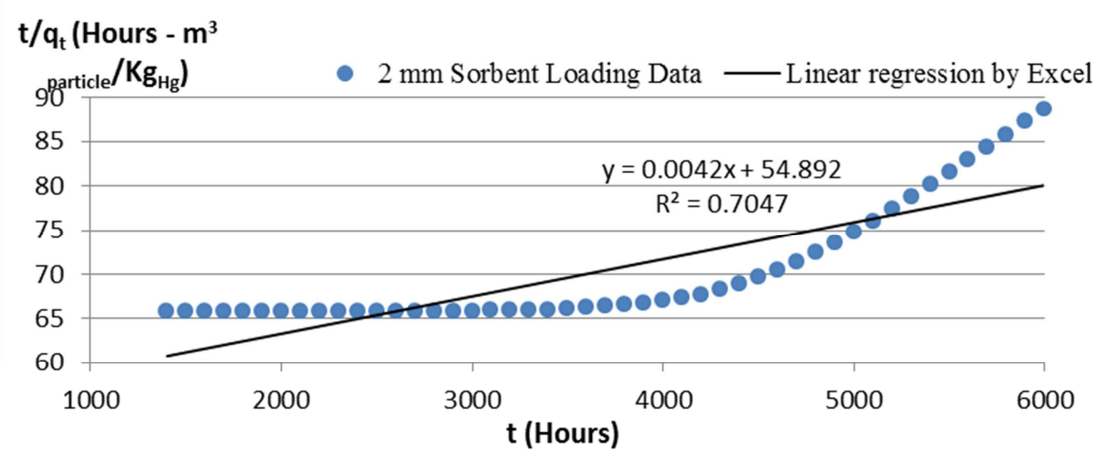

Fig. 9. Testing Pseudo-Second Order with $2 \mathrm{~mm}$ Adsorbent

Figures 8 and 9 indicate that the expression gives poor fit with $\mathrm{R}^{2}$ values of 0.5904 and 0.7047 at $4 \mathrm{~mm}$ and $2 \mathrm{~mm}$ particle size respectively.

\subsubsection{Testing Elovich's Model}

By plotting $q_{t}$ versus $\operatorname{Ln}(t)$, the following figures indicate the results of linear regression where it would be linear in case of conforming to the uptake rate formula. 


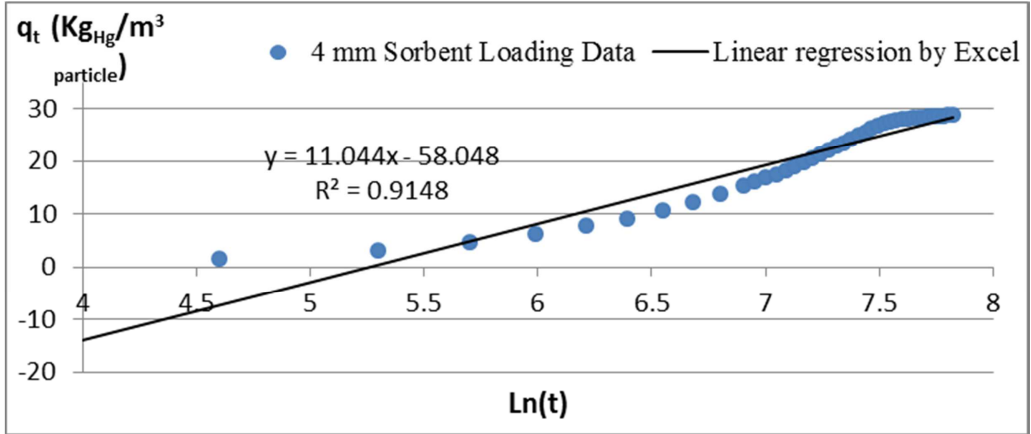

Fig. 10. Testing Elovich Model with 4 mm Adsorbent

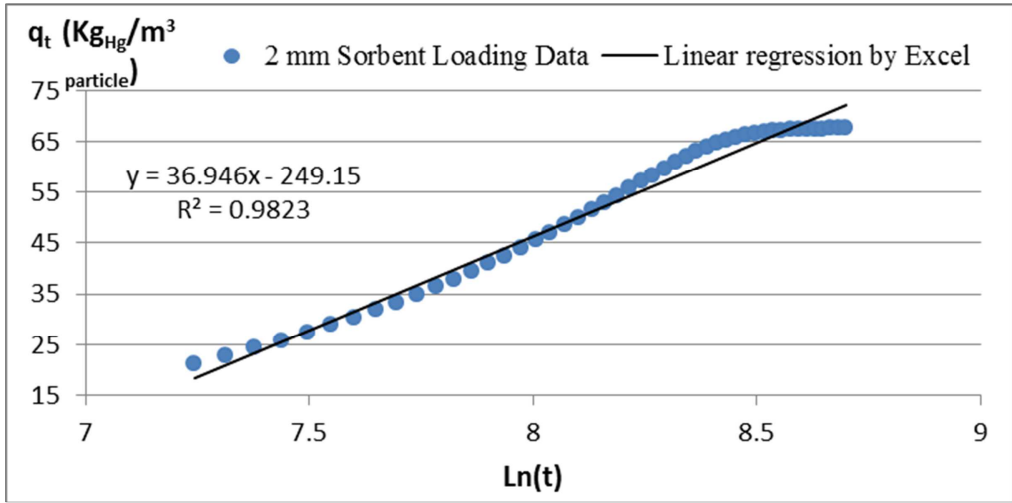

Fig. 11. Testing Elovich Model with 2 mm Adsorbent

Figures 10 and 11 show that the formula gives moderate fit with $\mathrm{R}^{2}$ value of 0.9148 at $4 \mathrm{~mm}$ particle size and much better fit with $\mathrm{R}^{2}$ value of 0.9823 at 2 $\mathrm{mm}$ particle size. This may indicate that the chemical reaction (chemisorption) is not the sole rate-limiting step at $4 \mathrm{~mm}$ size, while it might be the main ratelimiting step at smaller particles of $2 \mathrm{~mm}$.

\subsubsection{Testing Weber and Morris Model}

By plotting $q_{t}$ versus $\sqrt{t}$, the following figures indicate the results of linear regression where it would be linear in case of fitting the data to the proposed kinetics expression. 


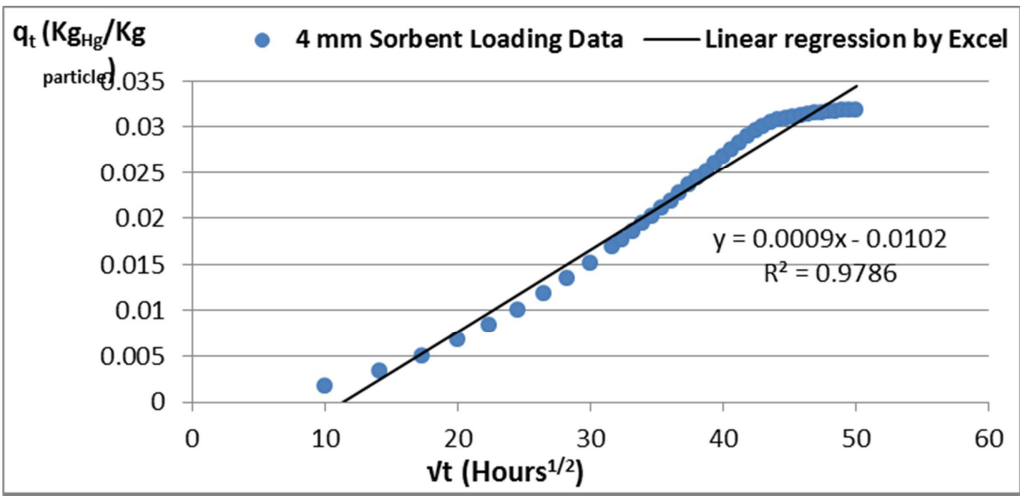

Fig. 12. Testing Weber \& Morris Model with 4 mm Adsorbent

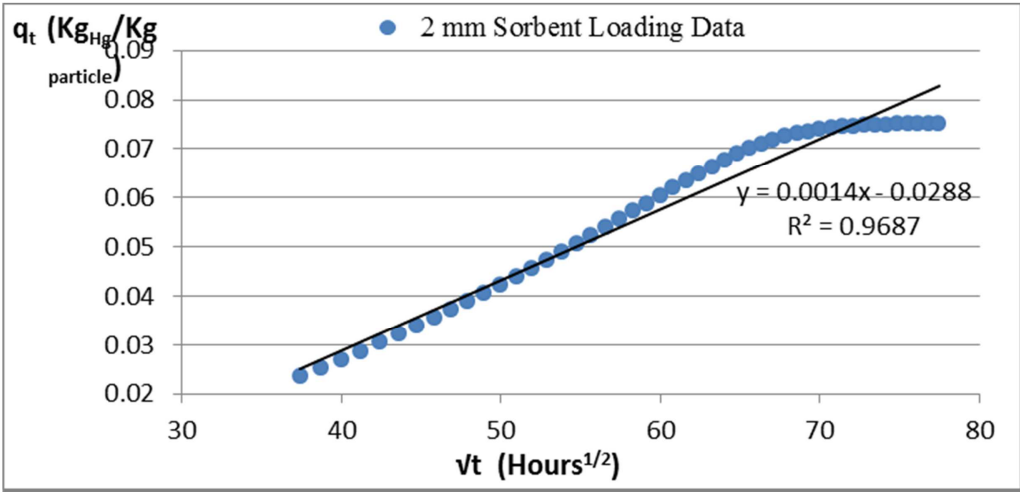

Fig. 13. Testing Weber \& Morris Model with 2 mm Adsorbent

Figures 12 and 13 show that the expression gives good fit with $\mathrm{R}^{2}$ values of 0.9786 and 0.9687 at $4 \mathrm{~mm}$ and $2 \mathrm{~mm}$ particle size respectively. This may indicate that intraparticle diffusion is a contributing rate-limiting step in both particles and more at the larger $4 \mathrm{~mm}$ particle.

\subsubsection{Testing Diffusion-Chemisorption Model}

By plotting $\sqrt{t} / q_{t}$ versus $\sqrt{t}$, the following figures indicate the results of linear regression where it would be linear in case of conforming the proposed rate equation. 


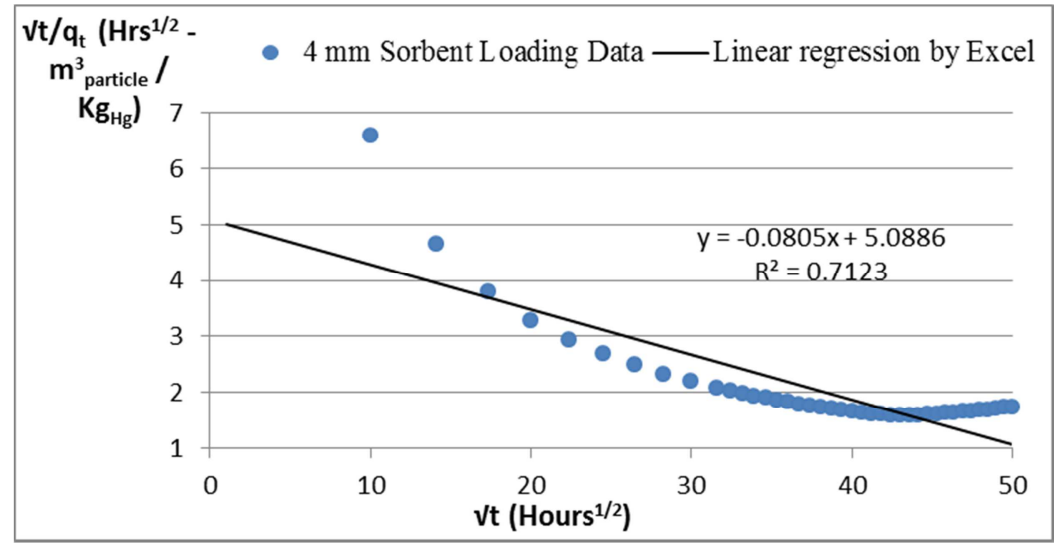

Fig. 14. Testing Diffusion-Chemisorption Model with 4 mm Adsorbent

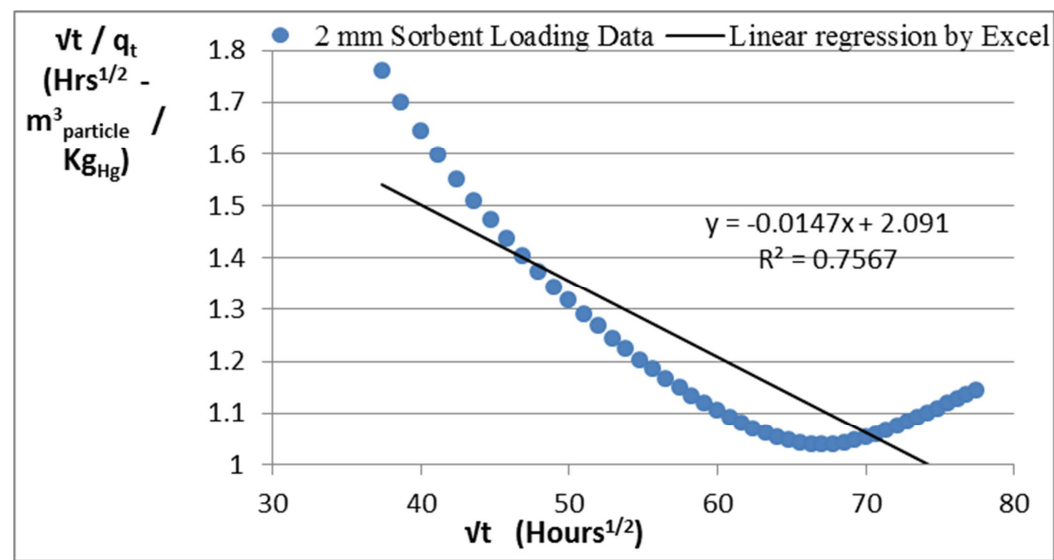

Fig. 15. Testing Diffusion-Chemisorption Model with $2 \mathrm{~mm}$ Adsorbent

Figures 14 and 15 show that the equation gives poor fit with $\mathrm{R}^{2}$ values of 0.7123 and 0.7567 at $4 \mathrm{~mm}$ and $2 \mathrm{~mm}$ particle size respectively.

\subsubsection{Testing Linear Driving Force Diffusion Model}

By plotting $\operatorname{Ln}(1-\alpha)$ versus $t$, the following figures indicate the results of linear regression where it would be linear in case of conforming the proposed rate equation. 


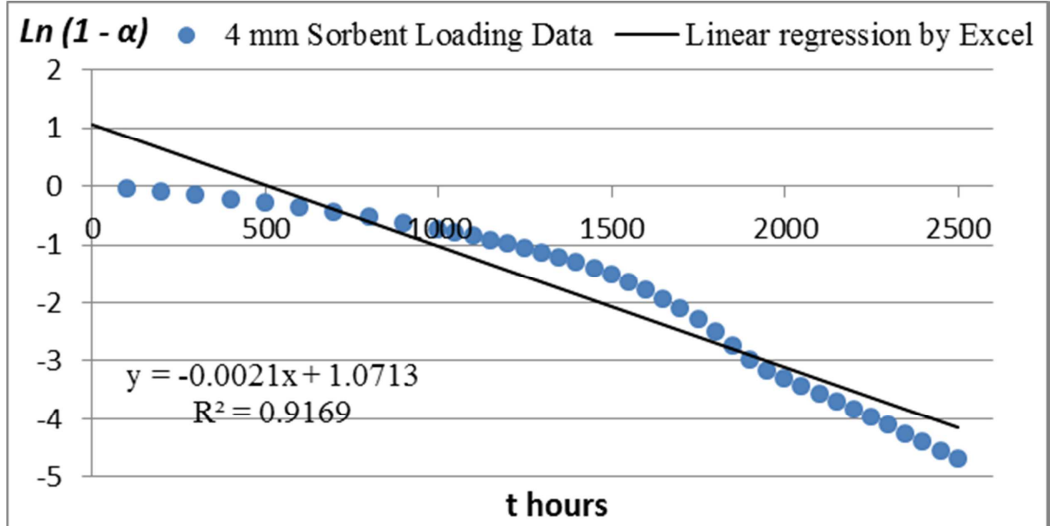

Fig. 16. Testing Linear Driving Force Diffusion Model with 4 mm Adsorbent

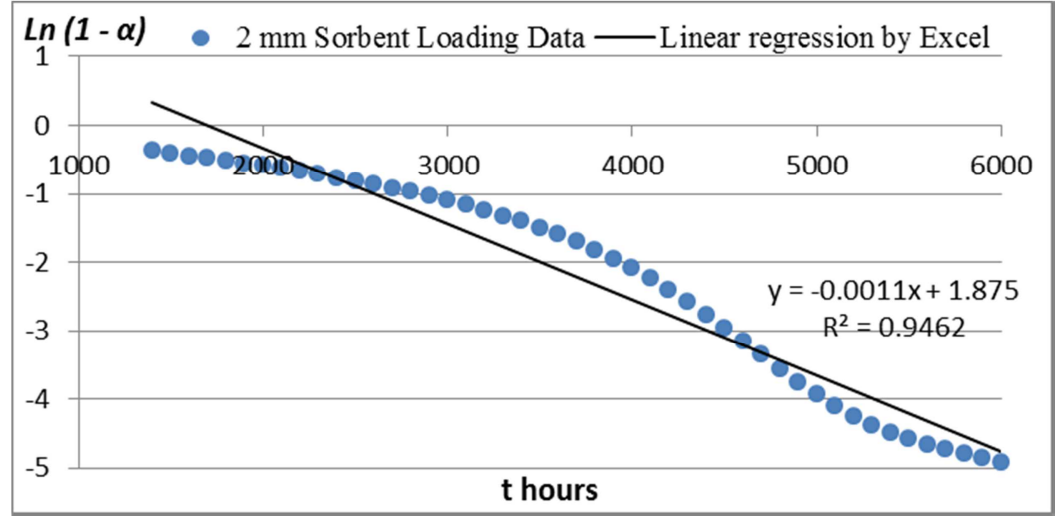

Fig. 17. Testing Linear Driving Force Diffusion Model with 2 mm Adsorbent

Figures 16 and 17 show that the expression gives moderate fit with $\mathrm{R}^{2}$ values of 0.9169 and 0.9462 at $4 \mathrm{~mm}$ and $2 \mathrm{~mm}$ particle size respectively with considering that $\alpha$ does not equal 1 .

According to the above kinetics analysis, the most fitting kinetics equations are Elovich model for chemisorption and Weber \& Morris model for intraparticle diffusion as a rate-limiting step with neglecting external film resistance.

\subsection{Studying Adsorption Mathematical Models}

\subsubsection{Testing Zhang \& Cheng Model}

As per the final linear form of solution, by plotting $\operatorname{Ln} \operatorname{Ln} \frac{C_{o}}{C}$ versus $t$, the following figures indicate the results of linear regression where it would be 
linear in case the model is fitting the breakthrough data with considering that $\frac{C_{o}}{C}$ does not equal 1.

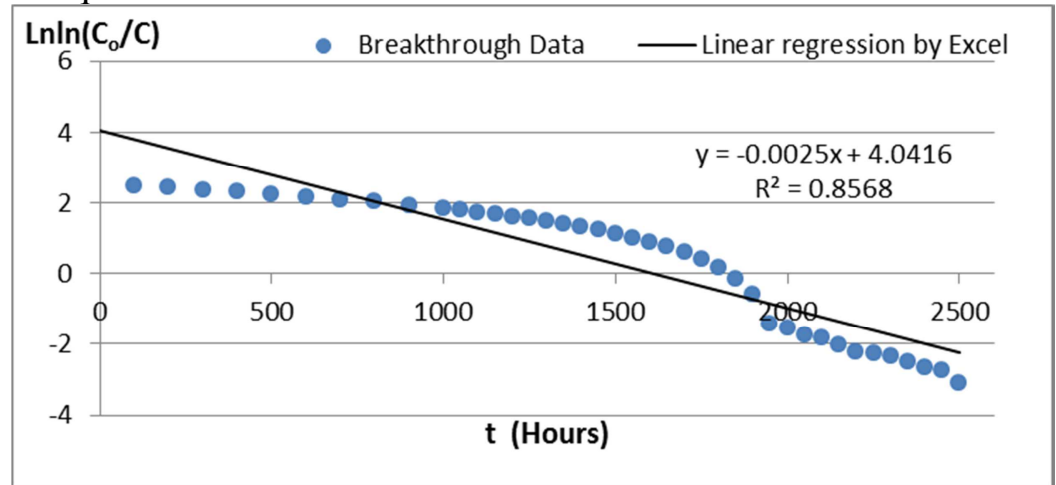

Fig. 18. Testing Zhang \& Cheng Model with 4 mm Adsorbent

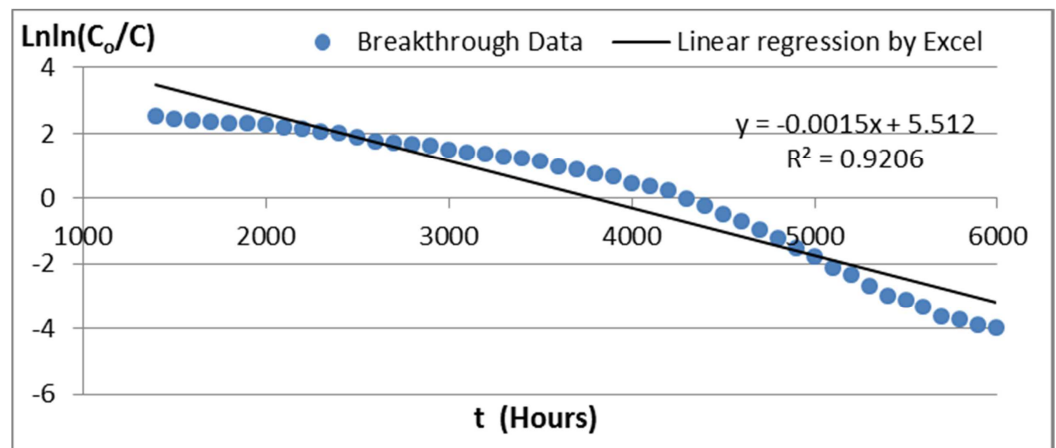

Fig. 19. Testing Zhang \& Cheng Model with $2 \mathrm{~mm}$ Adsorbent

Figures 18 and 19 show that the model is not fitting the breakthrough data with $\mathrm{R}^{2}$ values of 0.8568 and 0.9206 at $4 \mathrm{~mm}$ and $2 \mathrm{~mm}$ particle size respectively.

\subsubsection{Testing Wolborska Model}

As per the final linear form of solution, by plotting $\operatorname{Ln} \frac{C}{C_{o}}$ versus $t$, the following figures indicate the results of linear regression where it would be linear in case the model is fitting the breakthrough data. 


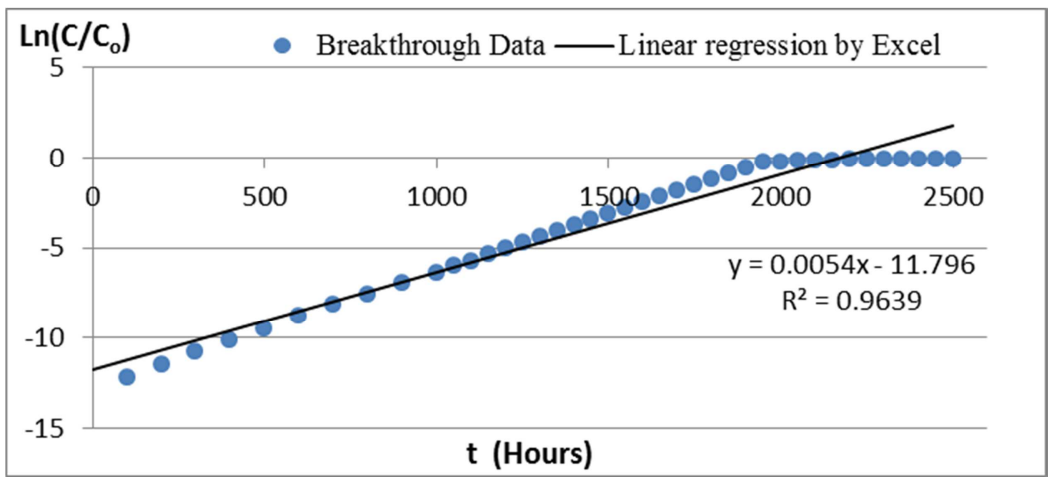

Fig. 20. Testing Wolborska Model with $4 \mathrm{~mm}$ Adsorbent

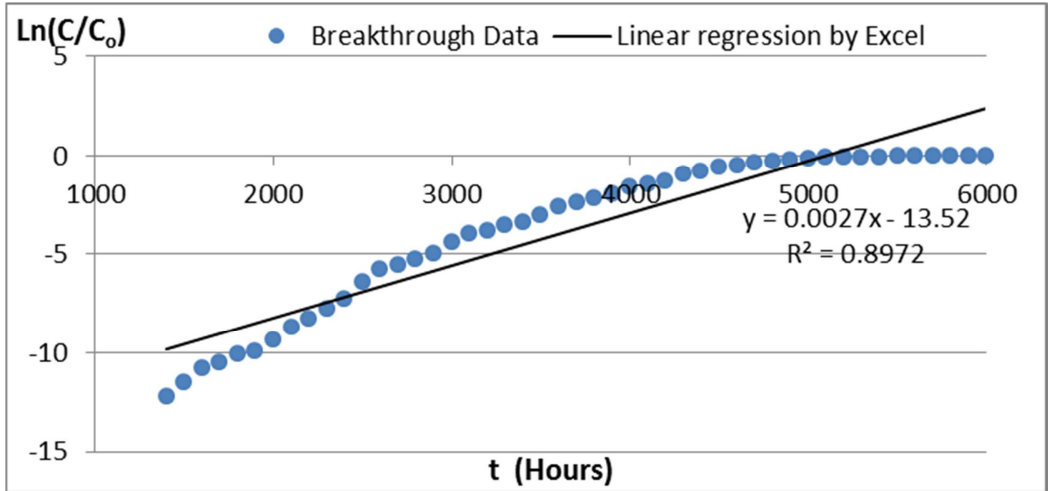

Fig. 21. Testing Wolborska Model with $2 \mathrm{~mm}$ Adsorbent

Figures 20 and 21 show that the model is not giving the best fit to both of the breakthrough data with $\mathrm{R}^{2}$ values of 0.9639 and 0.8972 at $4 \mathrm{~mm}$ and $2 \mathrm{~mm}$ particle size respectively.

\subsubsection{Testing Clark Model}

As per the final linear form of solution, by plotting $\operatorname{Ln}\left[\left(\frac{C_{g}}{C}\right)^{\wedge(n-1)}-1\right]$ versus $t$, the following figures indicate the results of linear regression where it would be linear in case the model is fitting the breakthrough data with considering that $\mathrm{n}$ does not equal 1 and $\frac{C_{o}}{C}$ does not equal 1 . 


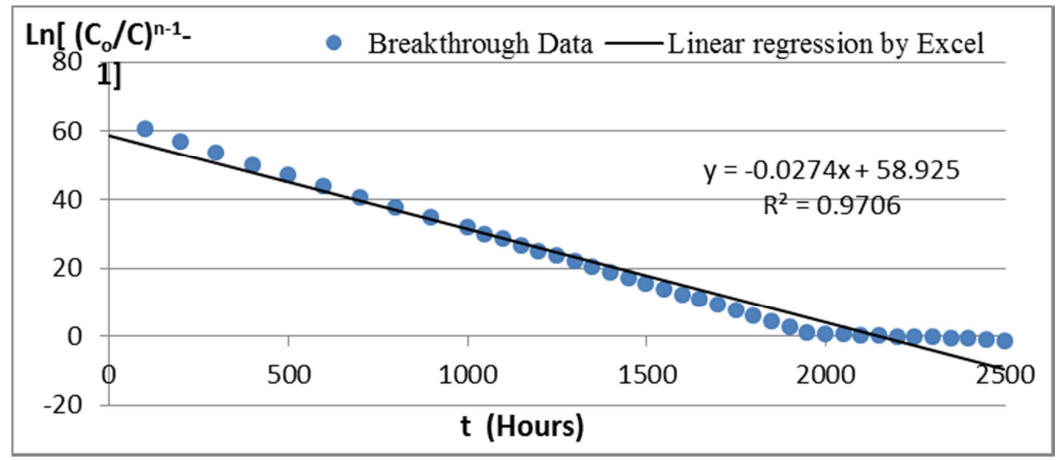

Fig. 22. Testing Clark Model with 4 mm Adsorbent

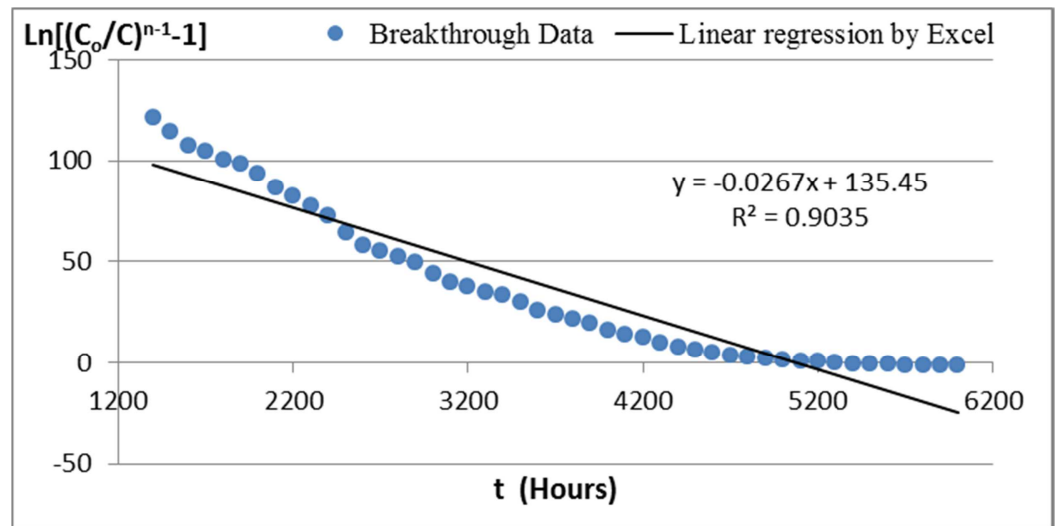

Fig. 23. Testing Clark Model with $2 \mathrm{~mm}$ Adsorbent

As shown in figures 22 and 23, for $4 \mathrm{~mm}$ particle, best fit is obtained by setting $\mathrm{n}=5.96$ as it was calculated from Fruendlich isotherm plots and $\mathrm{R}^{2}$ value is 0.9706 , while for $2 \mathrm{~mm}$ particle, best fit is obtained by setting $\mathrm{n}=10.9649$ as calculated from Fruendlich isotherm plots and $\mathrm{R}^{2}$ value is 0.9035 .

\subsubsection{Testing Bohart \& Adams Model}

As per the final linear form of solution, by plotting $\operatorname{Ln} \frac{C_{o}-C}{C} \operatorname{versus}\left(t-\frac{L}{v}\right)$, the following charts indicate the results of linear regression, where it would be linear in case of fitting the proposed model by Bohart \& Adams to the breakthrough data. 


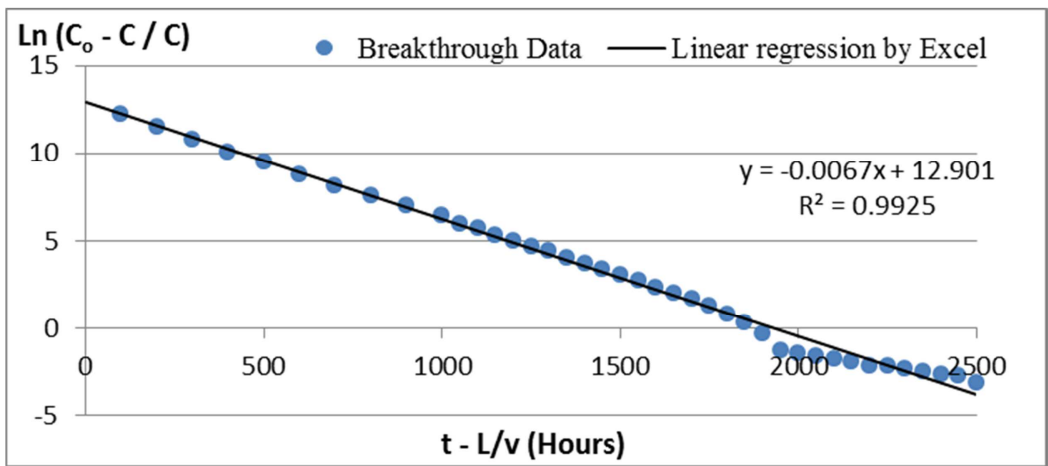

Fig. 24. Testing Bohart \& Adams Model with 4 mm Adsorbent

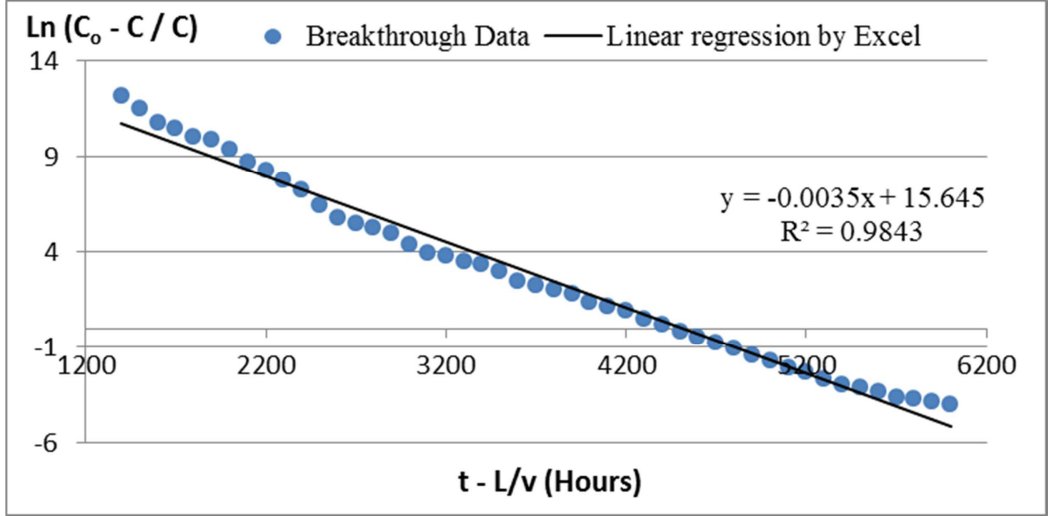

Fig. 25. Testing Bohart \& Adams Model with 2 mm Adsorbent

As shown in figures 24 and 25, Bohart-Adams model indicates best fit to the breakthrough data by high $\mathrm{R}^{2}$ values of 0.9925 and 0.9843 at $4 \mathrm{~mm}$ and $2 \mathrm{~mm}$ particle size respectively with considering that $C$ does not equal $C_{o}$. Accordingly, it can be used to describe the kinetics of mercury adsorption, simulate the bed's performance, calculate predictions with different parameters, and draw concentration profiles and breakthrough curves.

The following table summarizes $\mathrm{R}^{2}$ values resulted from linear regression of the different models.

Table. 3. $\mathrm{R}^{2}$ Values of Models Linear Regression

\begin{tabular}{|c|c|c|c|c|}
\hline Model & $\begin{array}{c}\text { Zhang \& } \\
\text { Cheng Model }\end{array}$ & $\begin{array}{c}\text { Wolborska } \\
\text { Model }\end{array}$ & Clark Model & $\begin{array}{c}\text { Bohart \& } \\
\text { Adams Model }\end{array}$ \\
\hline $\begin{array}{c}\mathbf{R}^{2} \\
\text { (4 mm particle) }\end{array}$ & 0.8568 & 0.9639 & 0.9706 & 0.9925 \\
\hline $\begin{array}{c}\mathbf{R}^{2} \\
\text { (2 mm particle) }\end{array}$ & 0.9206 & 0.8972 & 0.9035 & 0.9843 \\
\hline
\end{tabular}




\subsection{Bohart \& Adams Model's Predictability for the MRU System}

After the remarkable success of Bohart \& Adams model in best fitting to the breakthrough data by obtaining the highest $\mathrm{R}^{2}$ values of 0.9925 and 0.9843 in linear regression, the model has a considerable accuracy in prediction that can be utilized effectively in simulating the bed's performance with different operating conditions. However, figures 26 and 27 illustrate the model's accuracy in prediction by showing sufficient conformity between the actual equilibrium data and model's prediction.

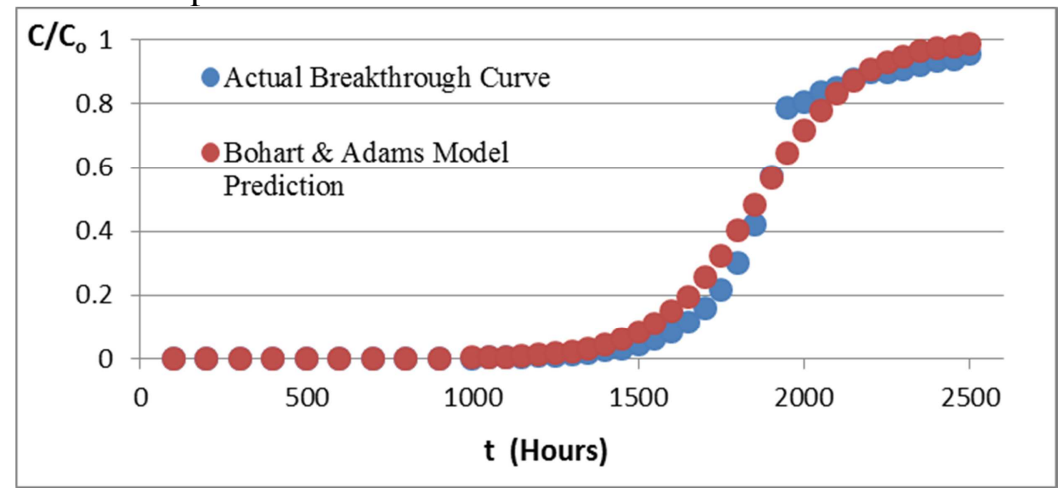

Fig. 26. Conformity of Bohart-Adams Model Prediction for $4 \mathrm{~mm}$ Adsorbent

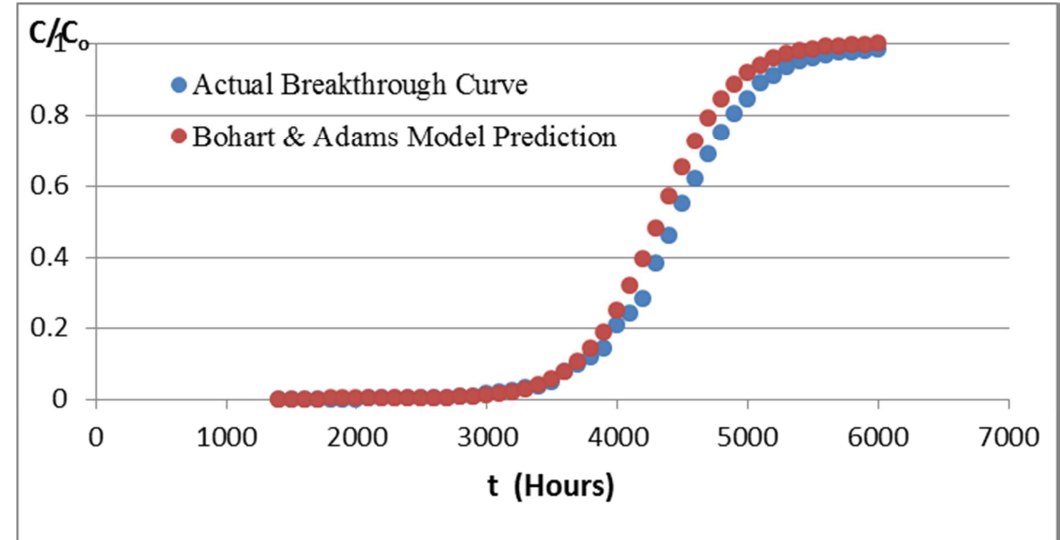

Fig. 27. Conformity of Bohart-Adams Model Prediction for $2 \mathrm{~mm}$ Adsorbent

\subsection{Simulating Performance of Original Bed Design versus the Current Skimmed Bed}

The bed is basically designed to treat a maximum of 1,350 MMSCFD feed gas flow rate contaminated with maximum of $20 \mu \mathrm{g} / \mathrm{Nm}^{3}$ mercury concentration. The following table summarizes the bed design basis. 
Table. 4. Design Basis of Mercury Guard Bed

\begin{tabular}{|c|c|}
\hline Maximum Feed Gas Flow Rate & $1,350 \mathrm{MMSCFD}$ \\
\hline Maximum Inlet Mercury Concentration & $20 \mu \mathrm{g} / \mathrm{Nm}^{3}$ \\
\hline Outlet Mercury Concentration & Below $0.01 \mu \mathrm{g} / \mathrm{Nm}^{3}$ \\
\hline Lifetime & 5 Years \\
\hline Bed Diameter & 5 Meters \\
\hline Bed Height & 2.50 Meters \\
\hline
\end{tabular}

The loading of the adsorbents actually ended at 2.48 meters bed height, and after start-up, the pressure drop across the bed increased dramatically to 2.75 bar at 1,165 MMSCFD and found that $75 \%$ of the pressure drop is concentrated across the top layer as shown in figure 28 .

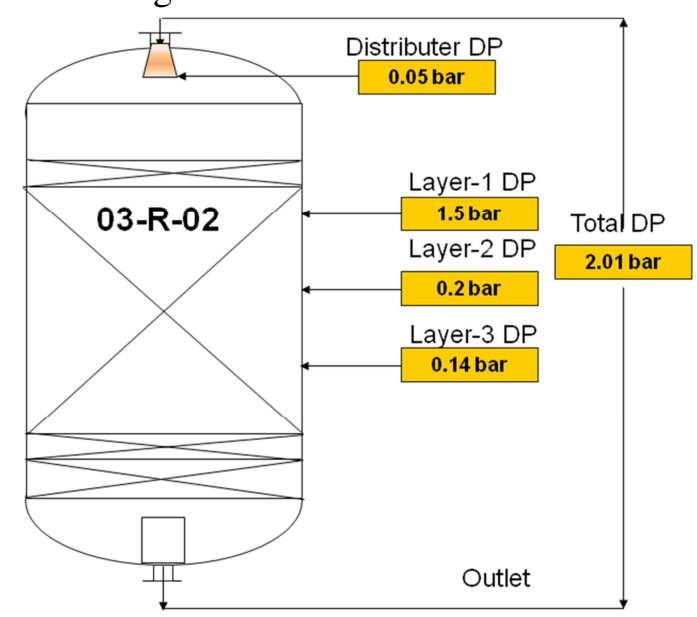

Fig. 28. Pressure Drop Distribution across Layers of MRU Bed

Consequently, a decision was taken to skim the top $500 \mathrm{~mm}$ layer of the mercury adsorbents and reload instead $500 \mathrm{~mm}$ of 2" inert ceramic balls to get better gas distribution, lower velocities, and lower vortices at the top of the catalyst. The modification was authorized by consulting the manufacturer and applying the required management of change procedures.

Bohart-Adams model equation was used to calculate service time prediction and evaluate the performance with the original bed height of 2.48 meters and 1.98 meters after the skimming. The following figures indicate the original bed height performance and lifetime, and the effect of skimming the top $500 \mathrm{~mm}$ layer. 


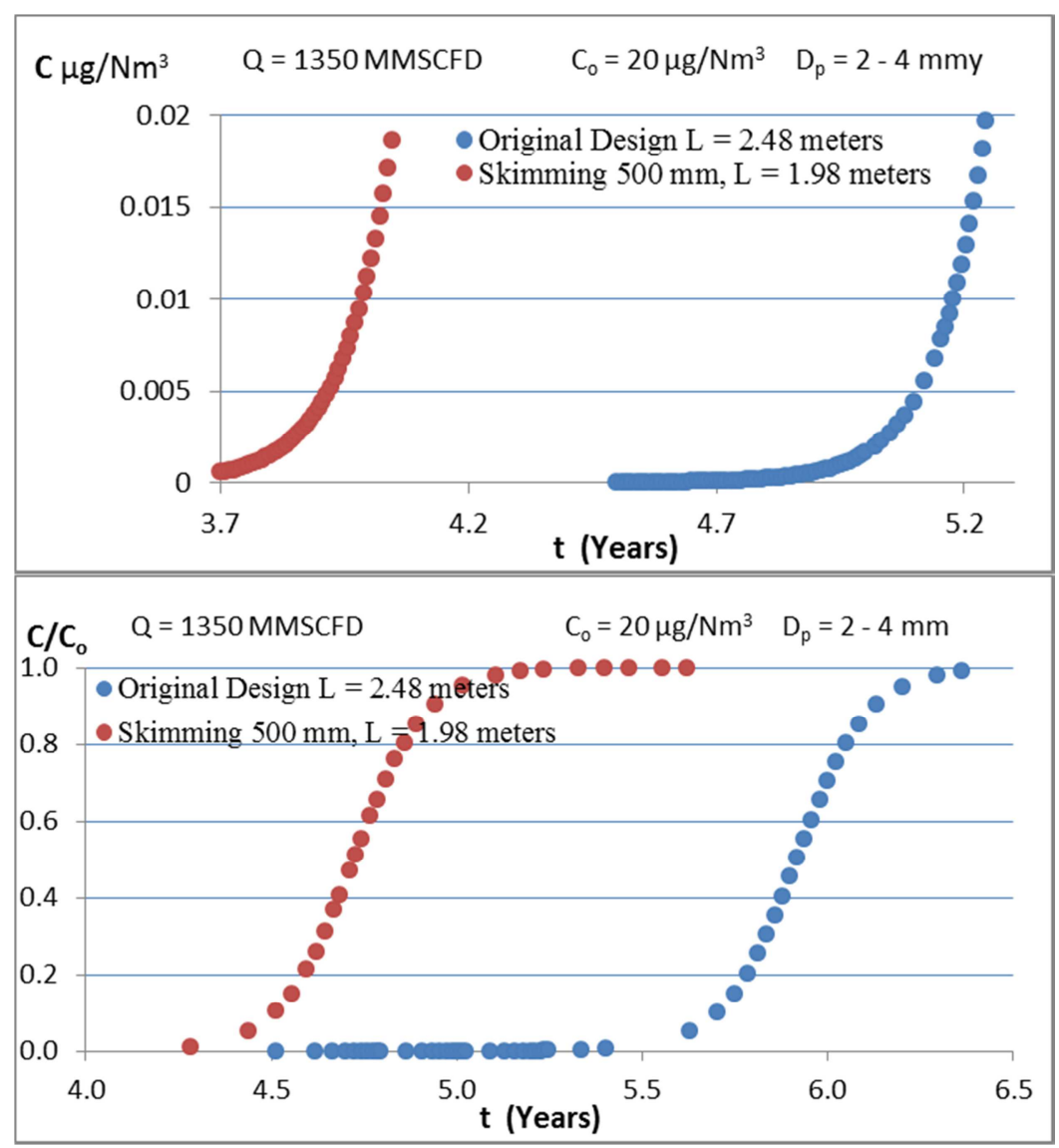

Fig. 29. Predicted Breakthrough Curves for Bed Design and Modification

Figure 29 shows that, at 1,350 MMSCFD feed gas contaminated with $20 \mu \mathrm{g} /$ $\mathrm{Nm}^{3}$ of mercury, the model predicted breakthrough at 1,893 days (5.18 years) with bed height of 2.48 meters and 2-4 mm adsorbents, which is very close to the manufacturer data sheet. After skimming, the model predicted breakthrough at 1,458 days (about 4 years) with bed height of 1.98 meters and the same particles size.

\subsection{Effect of Different Variables - Sensitivity Analysis and Case Studies}

The following parameters where studied and evaluated their effects.

1. Varying adsorbent particle size (With constant flow rate of 1350 MMSCFD, inlet mercury concentration $20 \mu \mathrm{g} / \mathrm{Nm}^{3}$, and bed height 1.98 meters). 
2. Varying inlet mercury concentration (With constant flow rate of 1350 MMSCFD, bed height 1.98 meters, and particles size of 2-4 mm).

3. Varying feed gas flow rate - velocity (With constant mercury concentration $20 \mu \mathrm{g} / \mathrm{Nm}^{3}$, bed height 1.98 meters, and particles size of 2-4 mm).

4. Varying bed height (With constant flow rate of 1350 MMSCFD, inlet mercury concentration $20 \mu \mathrm{g} / \mathrm{Nm}^{3}$, and particles size of 2-4 mm).

\subsubsection{Adsorbent Particle Size}

Figure 30 shows that the smaller particle size of $2 \mathrm{~mm}$ exhibits much better performance and longer lifetime due to improvement of the mercury diffusivity into the active sites compared to $4 \mathrm{~mm}$ size by the effects of increasing surface area, decreasing pore depth, and decreasing tortuosity, which lead to decreasing

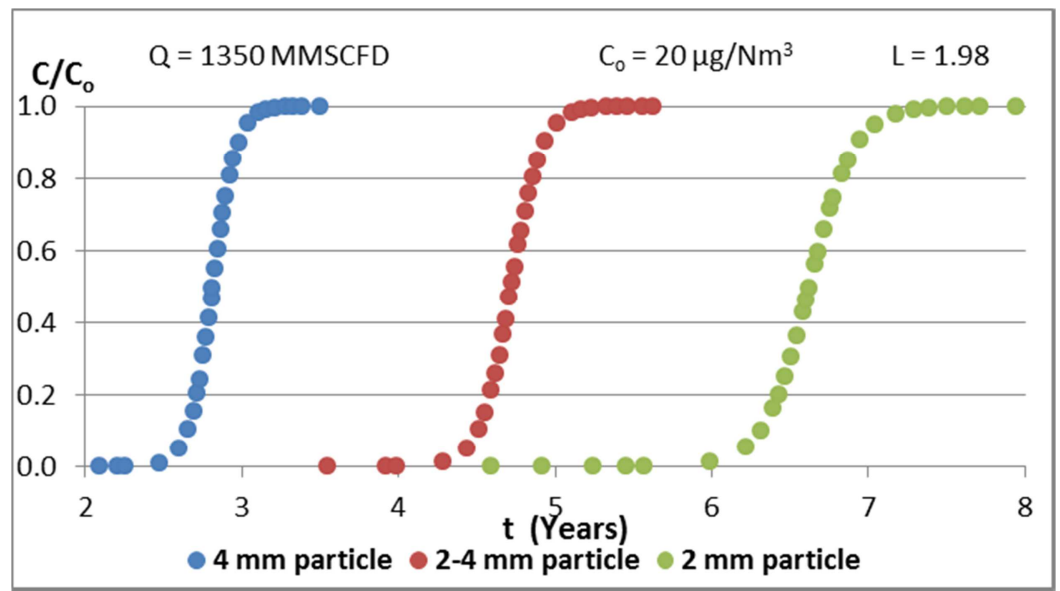

Fig. 30. Simulated Breakthrough Curves for Different Particle Sizes

intraparticle diffusion resistance, and increase adsorbent capacity. The model predicted breakthrough after 5.55 years, 3.98 years, and 2.25 years by using 2 $\mathrm{mm}, 2-4$ range $\mathrm{mm}$, and $4 \mathrm{~mm}$ particles respectively. However, due to pressure drop limitations, the bed is packed with a range of $2-4 \mathrm{~mm}$ adsorbents to compensate between the merits of small size (better mass transfer, longer lifetime) and the disadvantages of lower crush strength, lower bed porosity, and higher dust formation which all contribute to increase the pressure drop across the bed.

\subsubsection{Inlet Mercury Concentration}

Figure 31 shows that the higher mercury concentration quickly propagates through the bed with saturating the adsorbents and earlier breakthrough occurs 
in comparison to lower concentrations. Model predicted breakthrough after 2.63 years, 3.16 years, 3.98 years, 5.34 years at inlet mercury concentration of 30, 25, $20,15 \mu \mathrm{g} / \mathrm{Nm}^{3}$ respectively, while breakthrough is expected after 16.5 years for concentrations below $5 \mu \mathrm{g} / \mathrm{Nm}^{3}$.
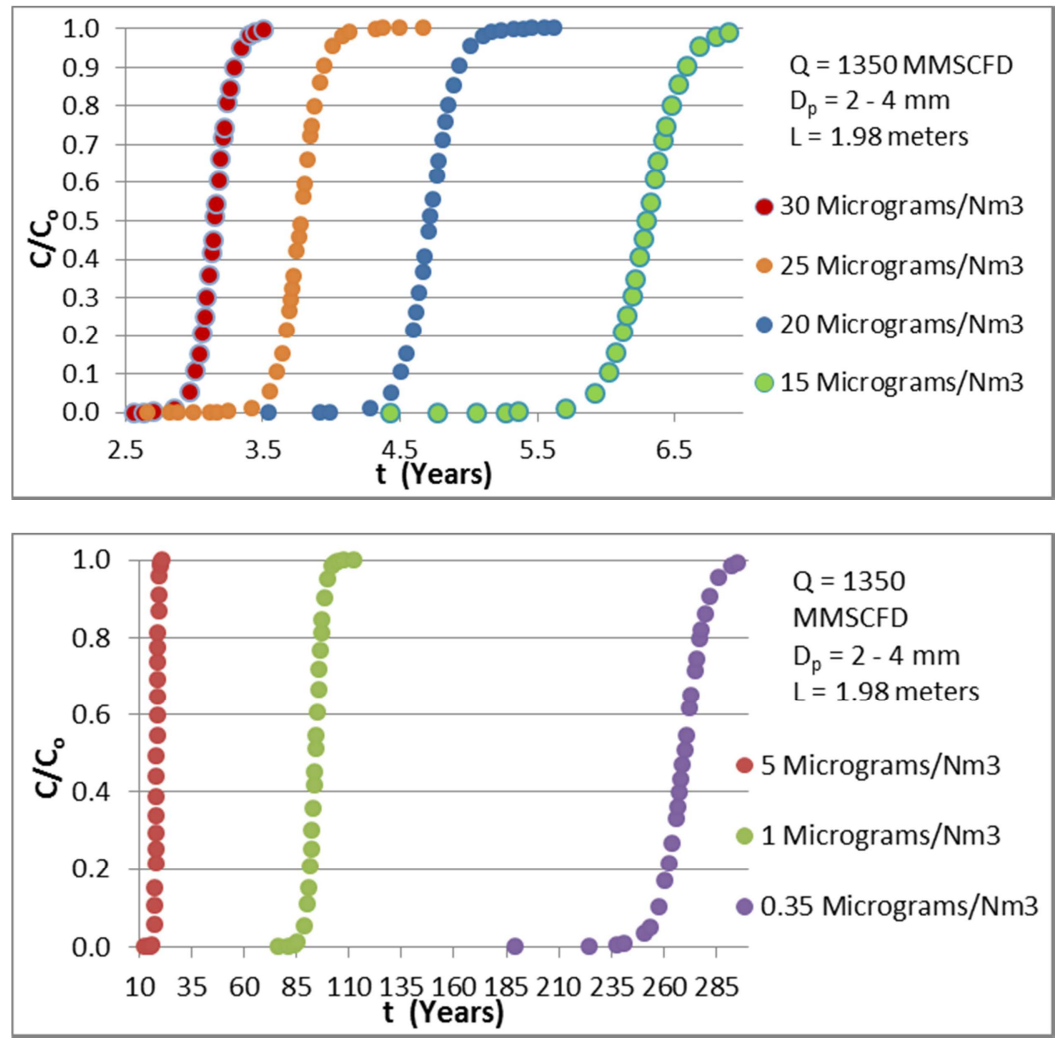

Fig. 31. Simulated Breakthrough Curves for Different Concentrations

\subsubsection{Feed Gas Flow Rate - Velocity}

Figure 32 shows that the effect of flow rate is similar to inlet mercury concentration where the higher flow rates quickly propagate through the bed with saturating the adsorbents and earlier breakthrough occurs in comparison to lower flow rates. Moreover, increasing the flow rate leads to decreasing contact time between gas and solid phases and accordingly reducing the available chance of mercury molecules to transport from gas phase to the surface of the sorbent, then diffuse into the pores, and react with active sites. However, only flow rates within the bed design range were evaluated by the model. Breakthrough is predicted to occur after 3.98 years, 5.06 years, 6.34 years, 8.37 
years, and 10.84 years at 1350, 1100, 900, 700, and 550 MMSCFD feed gas flow rate respectively.
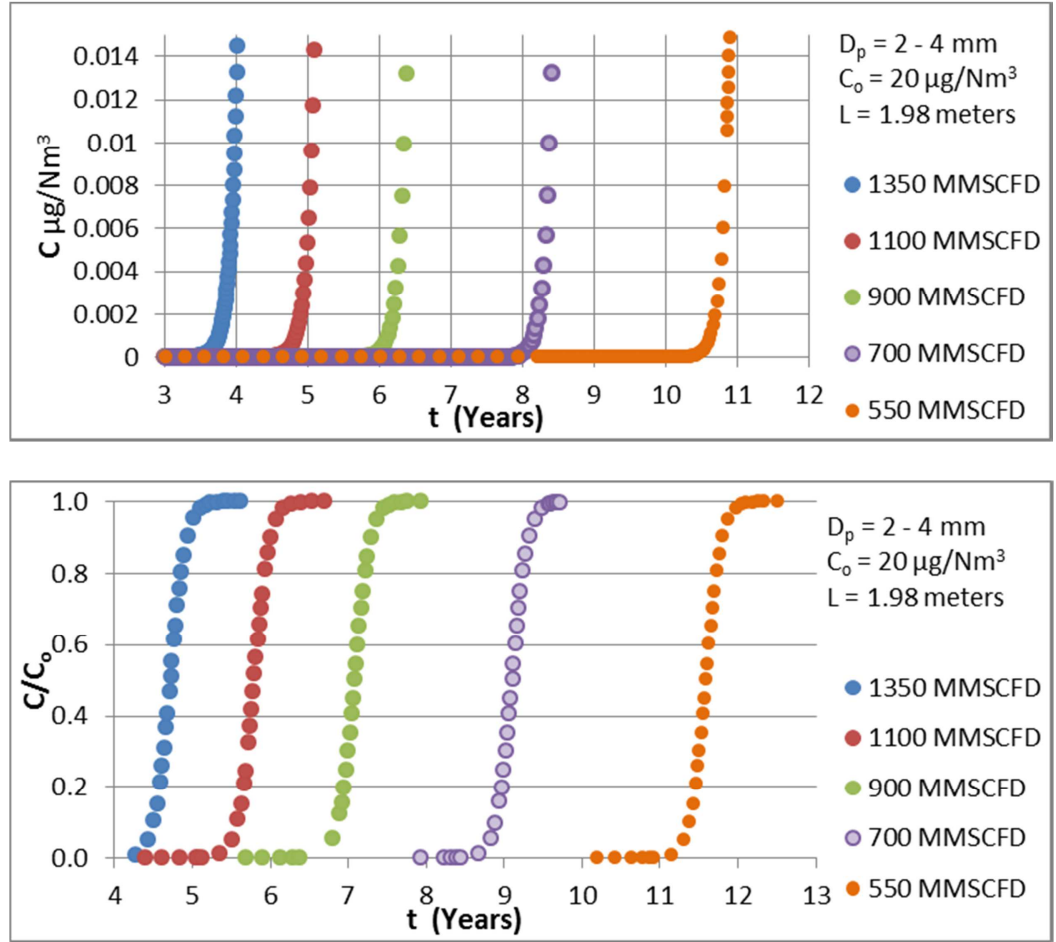

Fig. 32. Simulated Breakthrough Curves for Flow Rate Effect

\subsubsection{Bed Height}

Higher bed length means two effects; the first one is much adsorbents quantity, which leads to much available adsorption capacity and accordingly longer lifetime. The second effect is increasing contact time between gas and solid phases and accordingly maximizing the available chance of mercury molecules to transport from gas phase to the surface of the sorbent and then diffuse into the pores and react with active sites. However, various bed lengths are evaluated with the maximum of 2.48 meters for original bed design due to pressure drop limitations.

The model predicted breakthrough to occur after 5.17 years, 3.98 years, 2.83 years, 1.99 years, 1.17 years, and 78 days at bed height of $2.48,1.98,1.5,1.15$, 0.8 , and 0.4 meters respectively. 


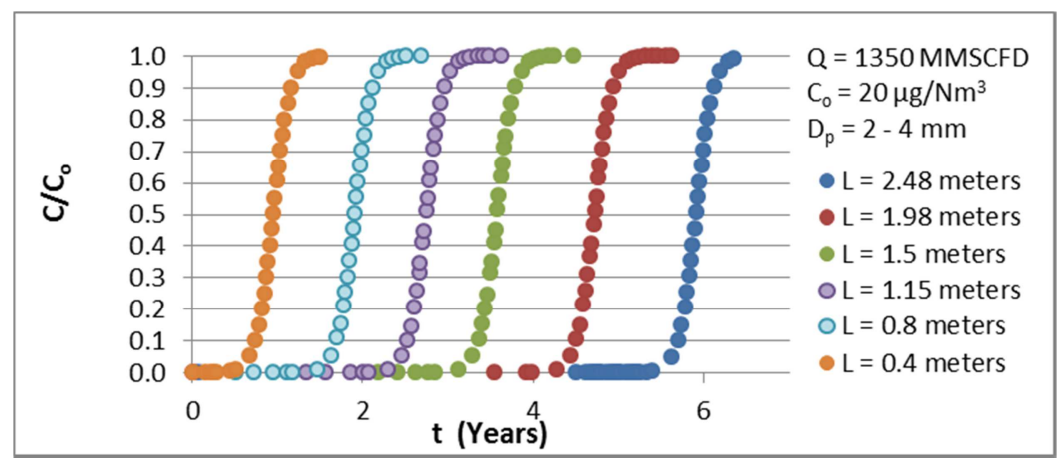

Fig. 33. Simulated Breakthrough Curves for Bed Height Effect

\section{CONCLUSION}

An industrial mercury removal bed was studied by evaluating bed and adsorbents characteristics through applying equilibrium isotherms, various kinetics equations, and various adsorption mathematical models to the available equilibrium data. Langmuir and Freundlich isotherms were evaluated and found the system is characterized by an irreversible isotherm that can be perfectly represented by Langmuir isotherm.

The equilibrium data were additionally examined by testing six kinetics equations to get some information about the system. Elovich's model, for chemisorption, gives moderate fit with $\mathrm{R}^{2}$ value of 0.9148 at $4 \mathrm{~mm}$ particle size and much better fit with $\mathrm{R}^{2}$ value of 0.9823 at $2 \mathrm{~mm}$ particle size. This may indicate that the chemical reaction (chemisorption) is not the sole rate-limiting step at $4 \mathrm{~mm}$ size, while it might be the main rate-limiting step at smaller particles of $2 \mathrm{~mm}$. Weber \& Morris expression gives better fit with $\mathrm{R}^{2}$ values of 0.9786 and 0.9687 at $4 \mathrm{~mm}$ and $2 \mathrm{~mm}$ particle size respectively. This may indicate that intraparticle diffusion is a contributing rate-limiting step in both particles and more at the larger $4 \mathrm{~mm}$ particle with neglecting external film resistance.

Based on the results of isotherms and kinetics assessment, and for deeper analysis, four adsorption mathematical models were selected to test fitting of breakthrough curves and then apply simulation studies. Bohart \& Adams model indicated best fit to the breakthrough curves by $\mathrm{R}^{2}$ values of 0.9925 and 0.9843 at $4 \mathrm{~mm}$ and $2 \mathrm{~mm}$ particle size respectively with good match between the model's assumptions and the available bed information. Accordingly, it was used effectively to describe the kinetics of mercury adsorption, simulate the bed performance, calculate predictions with different parameters, and draw concentration profiles and breakthrough curves. 
Model prediction for bed's design-basis was examined and found good match with manufacturer's data-sheet. The bed faced a problem of high pressure-drop in the beginning of operation, and then a layer of adsorbents was skimmed, so the new bed length was evaluated.

The model was used to simulate the bed performance with changes in operating parameters. Different gas flow rates, inlet mercury concentrations, adsorbent sizes, and bed heights were evaluated by sensitivity analysis of different case studies.

Based on simulation analysis, model prediction found that increasing the gas flow rate and the inlet concentration leads normally to faster saturation and earlier breakthrough similar to the effect of decreasing bed height (adsorbent quantity). The use of smaller particle size, of the adsorbent, increases adsorption efficiency due to improving surface area and mercury diffusivity into adsorbent pores, but the pressure drop limitations are considered in design.

Generally, the prediction results of high sorbent capacity and the historical field data of low mercury levels, which make the bed last for years of lifetime, revealed a valuable chance to improve gas treatment and maximize plant availability by optimizing bed design. A dual bed for efficient mercury removal with lower mercury bed height and added molecular-sieve layers can act as a guard to prevent occasional water breakthrough cases from the upstream dehydration beds and avoid hydrate formation in the cryogenic unit.

The justifications and advantages of this optimization chance are many and can be summarized in the following order.

Fortunately, the current feed gas resources are contaminated with mercury in the range of below 0.01 to $0.02 \mu \mathrm{g} / \mathrm{Nm}^{3}$ concentration since years. This is much below design load and, additionally, feed gas flow rate has been below the 1,350 MMSCFD. The maximum throughput of 1,350 MMSCFD did not last for long time and the rate is declining naturally with resources depletion.

As a general idea, the bed design can be optimized by dividing the configuration into a mercury guard bed and molecular sieves guard bed. Optimizing also the particles size is a beneficial option that can help, where using lower size offers higher surface area, lower intra-particle diffusion resistance (lower tortuosity), and therefore higher adsorption capacity. This can compensate for mercury removal efficiency, but without neglecting optimum bed porosity, and particles crush strength in order to avoid the increase in pressure-drop however, the mercury bed length will decrease.

This additional molecular sieves bed will act as a guard for water breakthrough cases that occur occasionally by many reasons such as process upsets in the 
plant, process upsets in upstream conditioning plants, problems in regeneration, high ambient temperatures in summer, and other various causes. Normally, when water breakthrough occurs, it is always a sudden condition and a proper action is taken after short time either by skipping some of regeneration time (shortening water adsorption time) or by decreasing feed gas flow rate. Such water breakthrough cases accumulate hydrate with time in cryogenic sections like strainers and exchangers until being difficult to be dissolved by methanol, and affect plant productivity, and then a dry-out operation for 24-36 hours is mandatory to remove all accumulated hydrate in the cryogenic unit. These molecular-sieves guard layers will save the high revenue losses of stopping production during 24-36 hours of regular dry-out, as the need of dry-out will be postponed for many years until saturating this guard bed. This guard is not normally loaded with water as the maximum breakthrough water content will be $0.1-0.2 \mathrm{ppm}(\mathrm{v})$ and last for maximum of 1 hour and occurs occasionally during the year. This proposal also protects the aluminum exchangers from all potential corrosion and stress mechanisms by other contaminants such as chlorides and acid gases that become active in presence of water. This guard also has an advantage of being not exposed to aging by hydrothermal conditions of regeneration.

Another major advantage is that eliminating the need of dry-out saves the plant and its equipment integrity. The dry-out exposes the cryogenic sections to hazardous thermal stresses affecting the integrity and safe operation of plate-fin exchangers, thermal disturbance in flanges leading to the hazard of hydrocarbon leakage cases, and danger of mercury-aluminum amalgamation appears with the operating conditions of dry-out (above mercury melting point, which is approximately $-40^{\circ} \mathrm{C}$ ).

Moreover, formed hydrate is primarily attacked by methanol injection trials, which also lead to thermal stresses in the cold-box exchangers in addition to affecting the downstream petrochemical industry by undesired catalysts poisoning effects with methanol contamination.

Generally, this proposal has the objective to work efficiently for both mercury removal up to inlet concentration of $5-10 \mu \mathrm{g} / \mathrm{Nm}^{3}$ design basis and capturing all water breakthrough cases as a guard for years based on the maximum feed gas flow rate of 1,350 MMSCFD to improve gas treatment and maximize plant availability. 


\section{REFERENCES}

1. Yang, H, Xu, Z, Fan, M, Bland, AE and Judkins, RR 2007. Adsorbents for capturing mercury in coal-fired boiler flue gas. Journal of Hazardous Materials 146(1), 1-11.

2. Hsi, HC and Chen, CT 2012. Influences of acidic/oxidizing gases on elemental mercury adsorption equilibrium and kinetics of sulfurimpregnated activated carbon. Fuel 98, 229-235.

3. Sasmaz, E et al. 2012. Mercury chemistry on brominated activated carbon. Fuel 99, 188-196.

4. Wade, CB, Thurman, C, Freas, W, Student, J, Matty, D and Mohanty, DK 2012. Preparation and characterization of high efficiency modified activated carbon for the capture of mercury from flue gas in coal-fired power plants. Fuel processing technology 97, 107-117.

5. Guo, $\mathrm{P}, \mathrm{Guo}, \mathrm{X}$ and Zheng, $\mathrm{C} 2010$. Roles of $\gamma-\mathrm{Fe}_{2} \mathrm{O}_{3}$ in fly ash for mercury removal: results of density functional theory study. Applied Surface Science 256(23), 6991-6996.

6. Baltrus, JP et al. 2010. Surface characterization of palladium-alumina sorbents for high-temperature capture of mercury and arsenic from fuel gas. Fuel 89(6), 1323-1325.

7. Graydon, JW, Zhang, X, Kirk, DW and Jia, CQ 2009. Sorption and stability of mercury on activated carbon for emission control. Journal of hazardous materials 168(2), 978-982.

8. Chung, ST, Kim, KI and Yun, YR 2009. Adsorption of elemental mercury vapor by impregnated activated carbon from a commercial respirator cartridge. Powder Technology 192(1), 47-53.

9. Ren, J, Zhou, J, Luo, Z, Zhong, Y and Xu, Z 2007. Fixed-bed experiments and mathematical modeling for adsorption of mercury vapor. Challenges of Power Engineering and Environment, Springer, Berlin, Heidelberg, 843849.

10. Camargo, CLM, de Resende, NS, de Oliveira, AG, Salim, VMM and Tavares, FW 2014. Investigation of adsorption-enhanced reaction process of mercury removal from simulated natural gas by mathematical modeling. Fuel 129, 129-137.

11. Skodras, G, Diamantopoulou, I, Natas, P, Orfanoudaki, T, Amarantos, P, Stavropoulos, GG and Sakellaropoulos, GP 2003. Mercury and PCBs adsorption on activated carbons: Experimentation and modelling. In 8th International Conference on Environmental Science and Technology, Lemnos island, Greece, September, 8-10. 
12. Meserole, FB, Chang, R, Carey, TR, Machac, J and Richardson, CF 1999. Modeling mercury removal by sorbent injection. Journal of the Air \& Waste Management Association 49(6), 694-704.

13. Flora, JR, Hargis, RA, O'Dowd, WJ, Pennline, HW and Vidic, RD 2003. Modeling sorbent injection for mercury control in baghouse filters: Imodel development and sensitivity analysis. Journal of the Air \& Waste Management Association 53(4), 478-488.

14. Flora, JR, Hargis, RA, O’Dowd, WJ, Pennline, HW and Vidic, RD 2003. Modeling sorbent injection for mercury control in baghouse filters: IIPilot-scale studies and model evaluation. Journal of the Air \& Waste Management Association 53(4), 489-496.

15. Chen, S, Rostam-Abadi, M and Chang, R 1996. Mercury removal from combustion flue gas by activated carbon injection: mass transfer effects.

Preprints of Papers, American Chemical Society, Division Fuel Chemistry 41, 442-446.

16. Rostam-Abadi, M, Chen, SG, Hsi, HC, Rood, M, Chang, R, Carey, T, Hargrove, B, Richardson, C, Rosenhoover, W and Meserole, F 1997. Novel vapor phase mercury sorbents. Proceedings of the EPRI-DOE-EPA Combined Utility Air Pollutant Control, 25-29.

17. Serre, SD, Gullett, BK and Ghorishi, SB 2001. Entrained-flow adsorption of mercury using activated carbon. Journal of the Air \& Waste Management Association 51(5), 733-741.

18. Scala, F 2001. Simulation of mercury capture by activated carbon injection in incinerator flue gas. 1. In-duct removal. Environmental science \& technology 35(21), 4367-4372.

19. Scala, F 2001. Simulation of mercury capture by activated carbon injection in incinerator flue gas. 2. Fabric filter removal. Environmental science \& technology 35(21), 4373-4378.

20. Sugier, A and Villa, FL, Institut Francais Du Petrole, 1978. Process for removing mercury from a gas or a liquid by absorption on a copper sulfide containing solid mass. U.S. Patent 4,094,777.

21. YU, X, ZHU, L, GUO, B and HE, S 2008. Adsorption of mercury on laterite from Guizhou Province, China. Journal of Environmental Sciences 20(11), 1328-1334.

22. Luo, J, Hein, AM and Hwang, JY 2004. Adsorption of vapor phase mercury on various carbons. Journal of Minerals and Materials Characterization and Engineering 3(01), 13.

23. Eswaran, S, Stenger, HG and Fan, Z 2007. Gas-phase mercury adsorption rate studies. Energy \& fuels 21(2), 852-857. 
24. Steijns, M, Peppelenbos, A and Mars, P 1976. Mercury chemisorption by sulfur adsorbed in porous materials. Journal of colloid and interface science 57(1), 181-186.

25. Furuta, A, Sato, K, Sato, K, Matsuzawa, T and Ito, H, Jcg Corporation, 1991. Process for removal of mercury from a liquid hydrocarbon. U.S. Patent 5,037,552.

26. Panagiotou, T, Momncy, JR and Senior, CL 2000. Zeolite-based mercury sorbent-laboratory testing and modeling. Preprints of Papers- American Chemical Society, Division of Fuel Chemistry 220, U386-U386.

27. Vidic, RD 2002. Adsorption of elemental mercury by virgin and impregnated activated carbon. In: SenGupta, A (ed) Environmental Separation of Heavy Metals - Engineered Processes. Boca Raton, FL: Lewis Publishers, 15-44.

28. Ghorishi, B and Gullett, BK 1998. Experimental study on mercury sorption by activated carbons and calcium hydroxide. US Environmental Protection Agency, Air Pollution Prevention and Control Division.

29. Huawei, Z., Xiuli, L., Li, W. and Peng, L 2014. Characteristics and Stability of Mercury Vapor Adsorption over Two Kinds of Modified Semicoke. The Scientific World Journal 2014. 1-7.

30. Borderieux, S, Wu, CY, Bonzongo, JC and Powers, K 2004. Control of elemental mercury vapor in combustion systems using $\mathrm{Fe}_{2} \mathrm{O}_{3}$ nanoparticles. Aerosol and Air Quality Research 4(1), 74-90.

31. Liu, Y 2014. Elemental Mercury Removal from Flue Gas by Metal/Metal Oxide Decorated Graphene Oxide Composites, Doctoral dissertation. Alberta: University of Alberta.

32. Holmes, MJ, Pavlish, JH, Zhuang, Y, Benson, SA and Fritze, MJ 2004. Pilot-scale evaluation of activated carbon-based mercury control options for utilities burning lignite coal. Preprints of Papers-American Chemical Society, Division of Fuel Chemistry 49(1), 281.

33. Fryxell, GE, Skaggs, R and Parker, KE 2004. Novel nanoporous sorbents for removal of mercury. Abstracts of Papers of The American Chemical Society 227, U1088-U1089.

34. Crocker, CR, Benson, SA, Holmes, MJ, Zhuang, Y, Pavlish, JH and Galbreath, KC 2004. Comparison of sorbents and furnace additives for mercury control in low-rank fuel combustion systems. Preprints of PapersAmerican Chemical Society, Division of Fuel Chemistry 49(1), 289.

35. Wdowin, M, Wiatros-Motyka, MM, Panek, R, Stevens, LA, Franus, W and Snape, CE 2014. Experimental study of mercury removal from exhaust gases. Fuel 128, 451-457. 
36. Ballestero, D, Gómez-Giménez, C, García-Díez, E, Juan, R, Rubio, B and Izquierdo, MT 2013. Influence of temperature and regeneration cycles on $\mathrm{Hg}$ capture and efficiency by structured $\mathrm{Au} / \mathrm{C}$ regenerable sorbents. Journal of hazardous materials 260, 247-254.

37. Olson, ES, Dunham, GE, Sharma, RK and Miller, SJ 2000. Mechanisms of mercury capture and breakthrough on activated carbon sorbents. ACS Fuels 45, 886-889.

38. Wilcox, $\mathrm{J}$ et al. 2018. Mercury adsorption and oxidation in coal combustion and gasification processes. International Journal of Coal Geology 90, 4-20.

39. Daza, L, Mendioroz, S and Pajares, J 1991. Mercury adsorption by sulfurized fibrous silicates. Clays and Clay Minerals 39(1), 14-21.

40. Padak, B 2011. Mercury reaction chemistry in combustion flue gases from experiments and theory, Doctoral dissertation. Stanford, California: Stanford University.

41. De, M, Azargohar, R, Dalai, AK and Shewchuk, SR 2013. Mercury removal by bio-char based modified activated carbons. Fuel 103, 570-578.

42. Bae, KM, Kim, BJ and Park, SJ, 2014. Overlook of carbonaceous adsorbents and processing methods for elemental mercury removal. Carbon letters 15(4), 238-246.

43. Bisson, TM, Ong, ZQ, MacLennan, A, Hu, Y and Xu, Z 2015. Impact of Sulfur Loading on Brominated Biomass Ash on Mercury Capture. Energy \& Fuels 29(12), 8110-8117.

44. O'Dowd, WJ, Hargis, RA, Granite, EJ and Pennline, HW 2004. Recent advances in mercury removal technology at the National Energy Technology Laboratory. Fuel Processing Technology 85(6), 533-548.

45. Xie, J et al. 2014. Sn-Mn binary metal oxides as non-carbon sorbent for mercury removal in a wide-temperature window. Journal of colloid and interface science 428, 121-127.

46. You, X 2002. Sulfur Impregnation of Activated Carbon Through Hydrogen Sulfide Oxidation, Doctoral dissertation. Pittsburgh, Pennsylvania: University of Pittsburgh.

47. Izquierdo, MT et al. 2011. Tail-end $\mathrm{Hg}$ capture on $\mathrm{Au} /$ carbon-monolith regenerable sorbents. Journal of hazardous materials 193, 304-310.

48. Abad-Valle, P, Lopez-Anton, MA, Diaz-Somoano, M and MartinezTarazona, MR 2011. The role of unburned carbon concentrates from fly ashes in the oxidation and retention of mercury. Chemical engineering journal 174(1), 86-92.

49. Eldefrawy, MM, Kenawy, IM and El-Tabey, RM 2014. Application of Nanosized Mesoporous Aluminosilicates for Adsorption of $\mathrm{Hg}$ from Aqueous Solutions: Kinetic, Isotherm and Thermodynamic Studies. International Journal of Advanced Research 2(12), 764-781. 
50. Zakria, MH, Omar, AA and Bustam, MA 2016. Mercury Removal of Fluctuating Ethane Feedstock in a Large Scale Production by Sulphur Impregnated Activated Carbon. Procedia Engineering 148, 561-567.

51. Shafawi, A, Ebdon, L, Foulkes, M, Stockwell, P and Corns, W 2000. Preliminary evaluation of adsorbent-based mercury removal systems for gas condensate. Analytica Chimica Acta 415(1), 21-32.

52. Bingham, MD 1990. Field detection and implications of mercury in natural gas. SPE Production Engineering 5(02), 120-124.

53. Mokhatab, S, Mak, JY, Valappil, JV and Wood, DA 2013. Handbook of liquefied natural gas. Gulf Professional Publishing.

54. Mokhatab, S and Poe, WA 2012. Handbook of natural gas transmission and processing. Gulf Professional Publishing.

55. Eckersley, N 2010. Advanced mercury removal technologies. Hydrocarbon processing 89(1), 29.

56. Jubin, C and Ducreux, O 2014. Mercury Removal Units Operation at Frontend Location. Abu Dhabi International Petroleum Exhibition and Conference, Society of Petroleum Engineers, Abu Dhabi, UAE, November.

57. Freundlich, HMF 1906. Over the adsorption in solution. The Journal of Physical Chemistry 57(385471), 1100-1107.

58. Ruthven, DM 1984. Principles of adsorption and adsorption processes. Fredericton: John Wiley \& Sons.

59. Langmuir, I 1918. The adsorption of gases on plane surfaces of glass, mica and platinum. Journal of the American Chemical society 40(9), 1361-1403.

60. Lagergren, SK 1898. About the theory of so-called adsorption of soluble substances. Sven. Vetenskapsakad. Handingarl 24, 1-39.

61. Ho, YS and McKay, G 1998. Kinetic models for the sorption of dye from aqueous solution by wood. Process Safety and Environmental Protection 76(2), 183-191.

62. Ho, YS and McKay, G 1998. Kinetic model for lead (II) sorption on to peat. Adsorption science \& technology 16(4), 243-255.

63. Zeldowitsch, J 1934. On the mechanism of catalytic oxidation of CO to $\mathrm{MnO} 2$ [Über den mechanismus der katalytischen oxydation von $\mathrm{CO}$ an MnO2]. Acta physicochim. URSS 1, 364-449.

64. Weber, WJ and Morris, JC 1963. Kinetics of adsorption on carbon from solution. Journal of the Sanitary Engineering Division 89(2), 31-60.

65. Sutherland, C 2009. Removal of heavy metals from water using low-cost adsorbents: process development, Doctoral dissertation. Saint Augustine, Trinidad and Tobago: University of the West Indies 
66. Vinod, VP and Anirudhan, TS 2002. Sorption of tannic acid on zirconium pillared clay. Journal of Chemical Technology and Biotechnology 77(1), 92101.

67. Zhang, $\mathrm{H}$ and Cheng, D 2000. Mathematical model for a fixed bed adsorptive reactor. Carbon 38(6), 877-880.

68. Wolborska, A 1989. Adsorption on activated carbon of p-nitrophenol from aqueous solution. Water Research 23(1), 85-91.

69. Clark, RM 1987. Evaluating the cost and performance of field-scale granular activated carbon systems. Environmental science \& technology 21(6), 573-580.

70. Bohart, GS and Adams, EQ 1920. Some aspects of the behavior of charcoal with respect to chlorine. Journal of the American Chemical Society 42(3), 523-544.

71. Cooney, DO 1999. Adsorption design for wastewater treatment. Boca Raton, Florida, USA: CRC Pres.INC.

72. Ho, N 2012. Modeling hydrogen sulfide adsorption by activated carbon made from anaerobic digestion by-product, Doctoral dissertation. Toronto: University of Toronto.

\section{Nomenclature}

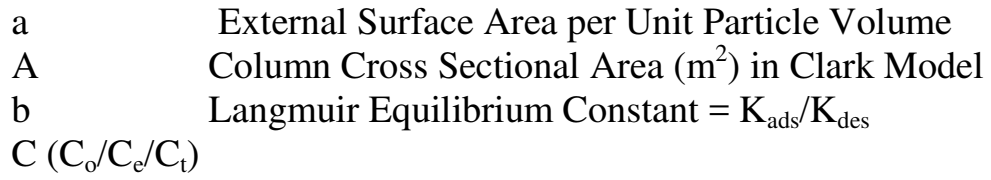

Adsorbate Concentration in Fluid Phase in mass of adsorbate / fluid volume units or mass of adsorbate / fluid mass units (Initial Concentration at Inlet / Concentration at Equilibrium / Concentration at Time $\mathrm{t}$ )

D Diffusivity and Diffusion Coefficients

$\mathrm{D}_{\mathrm{L}} \quad$ Axial Dispersion Coefficient

$\mathrm{D}_{\mathrm{m}} \quad$ Molecular Diffusion

DP Differential Pressure or Pressure Drop

$\mathrm{D}_{\mathrm{p}} \quad$ Particle Diameter

$\mathrm{H} \quad$ Bed Height

$\mathrm{h} \quad$ Initial Adsorption Rate in Pseudo-Second Order Kinetic Expression $\mathrm{h}=\mathrm{k} \mathrm{q}_{\mathrm{e}}^{2}$

J The Mass Transfer Rate per Unit Reactor Volume in Clark Model k/K Constants of Equilibrium and Kinetic Rate Expressions and Mass Transfer Coefficients 


$\begin{array}{ll}\text { L } & \text { Bed Length (Height) } \\ \text { LNG } & \text { Liquefied Natural Gas } \\ \mathrm{m} & \text { Mass of Adsorbent } \\ \text { MMSCFD } & \text { Million Standard Cubic Feet per Day } \\ \text { MRU } & \text { Mercury Removal Unit } \\ \mathrm{n} & \text { Constant in Freundlich Isotherm } \\ \text { ng } & \text { Nano Gram }\left(10^{-9} \text { Grams }\right) \\ \text { NGL } & \text { Natural Gas liquids } \\ \text { Nm }^{3} & \text { Normal Cubic Meters } \\ \text { PCBs } & \text { Polychlorinated Biphenyl } \\ \text { Q } & \text { Gas Flow Rate in Graphs }\end{array}$

$\mathrm{q}\left(\mathrm{q}_{\mathrm{s}} / \mathrm{q}_{\mathrm{o}} / \mathrm{q}_{\mathrm{e}} / \mathrm{q}_{\max } / \mathrm{q}_{\mathrm{t}}\right)$

Adsorbate Concentration in Solid Phase (Adsorbent) in mass of adsorbate / adsorbent volume units or mass of adsorbate / adsorbent mass units (Saturation / Initial / Equilibrium / Maximum Concentration/ Concentration at Time $\mathrm{t}$ )

$\mathrm{R} \quad$ Reaction Rate in Zhang \& Cheng Model

$\mathrm{R}_{\mathrm{p}} \quad$ Particle Radius

$\mathrm{R}^{2} \quad$ Coefficient of Determination

$\mathrm{t}, \mathrm{t}_{\mathrm{b}}, \mathrm{t}_{\mathrm{s}} \quad$ Time, Breakthrough Time, Saturation Time

$\mathrm{v}(\mathrm{v}) \quad$ Fluid Velocity

$\mathrm{x} \quad$ Distance and Axial Coordinates

z Distance and Axial Coordinates or Bed Height in Clark Model or Lumped Parameter in Bohart \& Adams Model

$\mu \mathrm{g} \quad$ Micro Gram $\left(10^{-6} \mathrm{Grams}\right)$

$\beta \quad$ Desorption Constant or The Relationship between Degree of Surface Coverage and Activation Energy of Chemisorption in Elovich Model or Kinetic Constant in Wolborska Model

$\epsilon \quad$ Porosity

$\alpha \quad$ Initial Adsorption Rate in Elovich Model or The Fractional Attainment of Equilibrium $\mathrm{q} / \mathrm{q}_{\mathrm{e}}$ in Vinod \& Anirudhan Model of Linear Driving Force Diffusion Model or Lumped Parameter in Zhang \& Cheng Model

$\Phi \quad$ Deactivation Function (dimensionless) in Zhang \& Cheng Model

$\theta$

Adsorbent Coverage in Langmuir Isotherm $\theta=\frac{\mathrm{q}}{\mathrm{q}_{\mathrm{s}}}=\frac{\mathrm{bc}}{1+\mathrm{bc}}$ or

Lumped Parameter in Zhang \& Cheng Model

t Lumped Parameter in Bohart \& Adams Model

Editor received the manuscript: 24.05 .2019 